\title{
User's Guide for TRANZ: A Data Transformation and Analysis Program
}

\author{
K. J. Fischer
}

December 1985

Prepared for the U.S. Department of Energy under Contract DE-AC06-76RLO 1830

Pacific Northwest Laboratory Operated for the U.S. Department of Energy by Battelle Memorial Institute 


\section{DISCLAIMER}

This report was prepared as an account of work sponsored by an agency of the United States Government. Neither the United States Government nor any agency thereof, nor any of their employees, makes any warranty, express or implied, or assumes any legal liability or responsibility for the accuracy, completeness, or usefulness of any information, apparatus, product, or process disclosed, or represents that its use would not infringe privately owned rights. Reference herein to any specific commercial product, process, or service by trade name, trademark, manufacturer, or otherwise, does not necessarily constitute or imply its endorsement, recommendation, or favoring by the United States Government or any agency thereof. The views and opinions of authors expressed herein do not necessarily state or reflect those of the United States Government or any agency thereof.

\section{PACIFIC NORTHWEST LABORATORY operated by \\ BATTELLE \\ for the \\ UNITED STATES DEPARTMENT OF ENERGY \\ under Contract DE-AC06-76RL.O 1830}

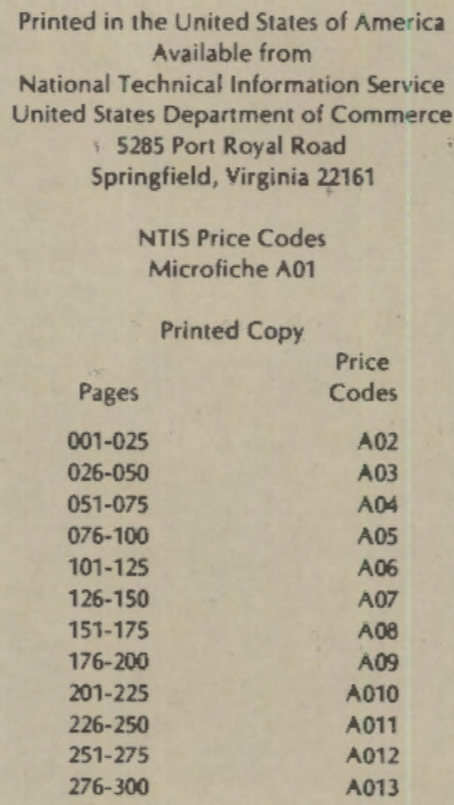


USER'S GUIDE FOR TRANZ: A DATA

TRANSFORMATION AND ANALYSIS PROGRAM

K. J. Fischer

December 1985

Prepared for the Bonneville Power Administration under a Related Services Agreement with the U.S. Department of Energy Contract DE-ACO6-76RLO 1830

Pacific Northwest Laboratory

Richland, Washington 99352 


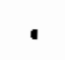

,

.

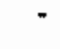




\section{FORWARD}

This report is one in a series of documents describing particular elements of the End-Use Load and Conservation Assessment Program (ELCAP), which is being conducted by Pacific Northwest Laboratory (PNL) for the Bonneville Power Administration (BPA). The project's objective is to efficiently and accurately compile hourly end-use energy consumption levels and characteristic data for buildings and residences in the Pacific Northwest. These data will be used to characterize the energy requirements and to refine the accuracy of estimates of conservation potential in residential housing stock throughout the Pacific Northwest.

The project entails the auditing and metering of 700 residences and 250 buildings throughout the BPA service area during 1984 and 1985 . The data will be configured into a data base management system to facilitate detailed analysis of building energy-use cause and effect. This report provides an insight into procedures used to ensure the quality of the data collected.

This report was prepared by Kenneth J. Fischer, a senior mechanical engineering student from Oregon State University, who participated in the summer intern program at PNL during 1984.

William F. Sandusky

ELCAP Installation Task Leader 
*

. 
SUMMARY

This report is a user's guide for TRANZ, a program developed by Pacific Northwest Laboratory (PNL) for an IBM PCo with a basic compiler, Version 2.0. The purpose of TRANZ is to convert, organize, and evaluate electrical end-use load data obtained from the Field Data Acquisition Systems (FDAS). These FDAS will be installed in commercial buildings and residences as part of the End-Use Load and Conservation Assessment Program (ELCAP) that is being managed by PNL for the Bonneville Power Administration (BPA). TRANZ has been developed with highly interactive menu-driven routines and requires little computer experience for prover operation. It is executable on a single or double disk drive IBM $P C$. The program can be used for spot checking data, troubleshooting installation problems, and preparing tabular and graphical summaries. Sample files and program output, and a program source code listing are provided as appendices.

The program itself contains six primary routines: The first routine converts the raw character byte data dumped from the FDAS into a formatted ASCII engineering unit file. The second routine checks the data to make sure that each value is within a reasonable range. The third routine sorts a file so that the records start at the earliest time and end at the latest time. The fourth routine appends two files for the same building or residence, removing any overlap in the files. The fifth routine summarizes the data in both a tabular and graphical form. The sixth routine generates a hard copy table of day numbers and their corresponding dates.

- IBM PC is a trademark of International Business Machines, Corp., Boca Raton, Florida. 


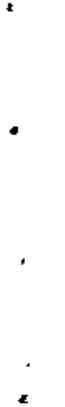




\section{CONTENTS}

FORWARD............................................ $i i_{i}$

SUMMARY.......................................... v

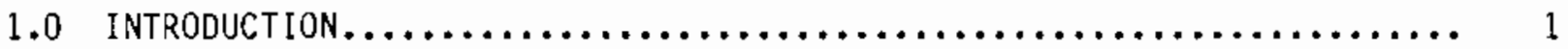

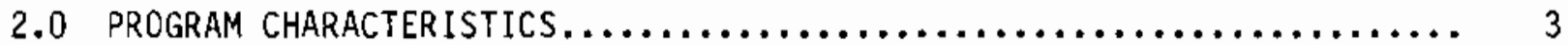

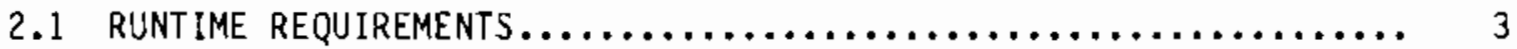

2.2 PROGRAM STRUCTURE.............................. 3

2.3 OISK DRIVE SPECIFICATION....................... 4

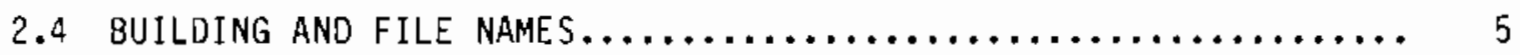

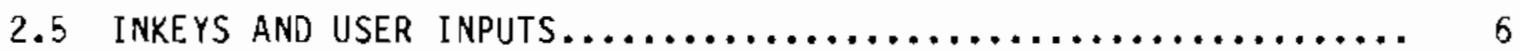

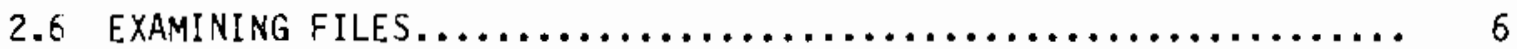

3.0 ROLITINE TO CONVERT RAW DATA TO ASCII ENGINEERING UNITS............ 9

4.0 ROUTINE TO CHECK DATA REASONABLENESS.................... 11

5.0 ROUTINE TO SORT A FILE CHRONOLOGICALLY................... 13

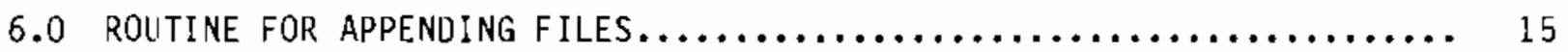

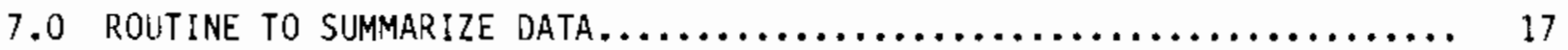

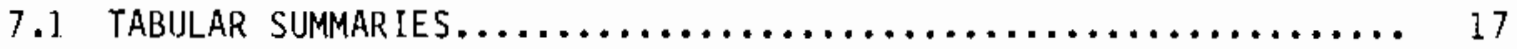

7.2 GRAPHICAL SUMMARIES.............................. 19

8.0 ROUTINE TO CREATE A TABLE OF DAY NuMBERS AND DATES ............. 23 APPENDIX A - SAMPLE FILES AND PROGRAM OUTPUT $\ldots \ldots \ldots \ldots \ldots \ldots \ldots \ldots \ldots \ldots \ldots \ldots$ APPENDIK B - PROGRAM LISTING FOR TRANPLUS.BAS $\ldots \ldots \ldots \ldots \ldots \ldots \ldots \ldots \ldots \ldots .$. 


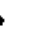

.

. 


\subsection{INTRODUCTION}

Pacific Northwest Laboratory (PNL) is managing the End-Use Load and Conservation Assessment Program (ELCAP) for the Bonneville Power Administration (BPA). To ensure the quality of the end-use data collected under the ELCAP effort, it is necessary to have techniques that can be used to support the data verification process. The verification process is required after the field Data Acquisition System (FDAS) has been installed in commercial buildings and residences. This process determines whether or not the data being acquired is accurate and representative of actual conditions. One method that can be used in the verification process is to list and plot acquired data for various time interva!s. It is desirable to have this process of either listing or plotting the data done independently of PNL's normal data acquisition and analysis tasks. To meet this objective, a Basic computer program, TRANZ, has been developed by PNL to operate on an IBM PC . This document provides a user's guide for TRANZ.

The program was created under Disk Operating System (DOS) Version 2.0 and is menu driven to facilitate its use. The program consists of a main module and six primary routines. These routines deal with various aspects of data processing, summarization, and presentation. The latter can be either in the listing or plotting mode. A flow diagram of the program is illustrated in Figure 1.

Sample input files and program output, and a program source code listing are provided in Appendices $A$ and $B$, respectively, to document correct operation of the program. The program is structured in such a manner that it can be easily converted to other PC types.

(7) IBM PC is a trademark of the International Business Machines, Corp., Boca Raton, Florida. 


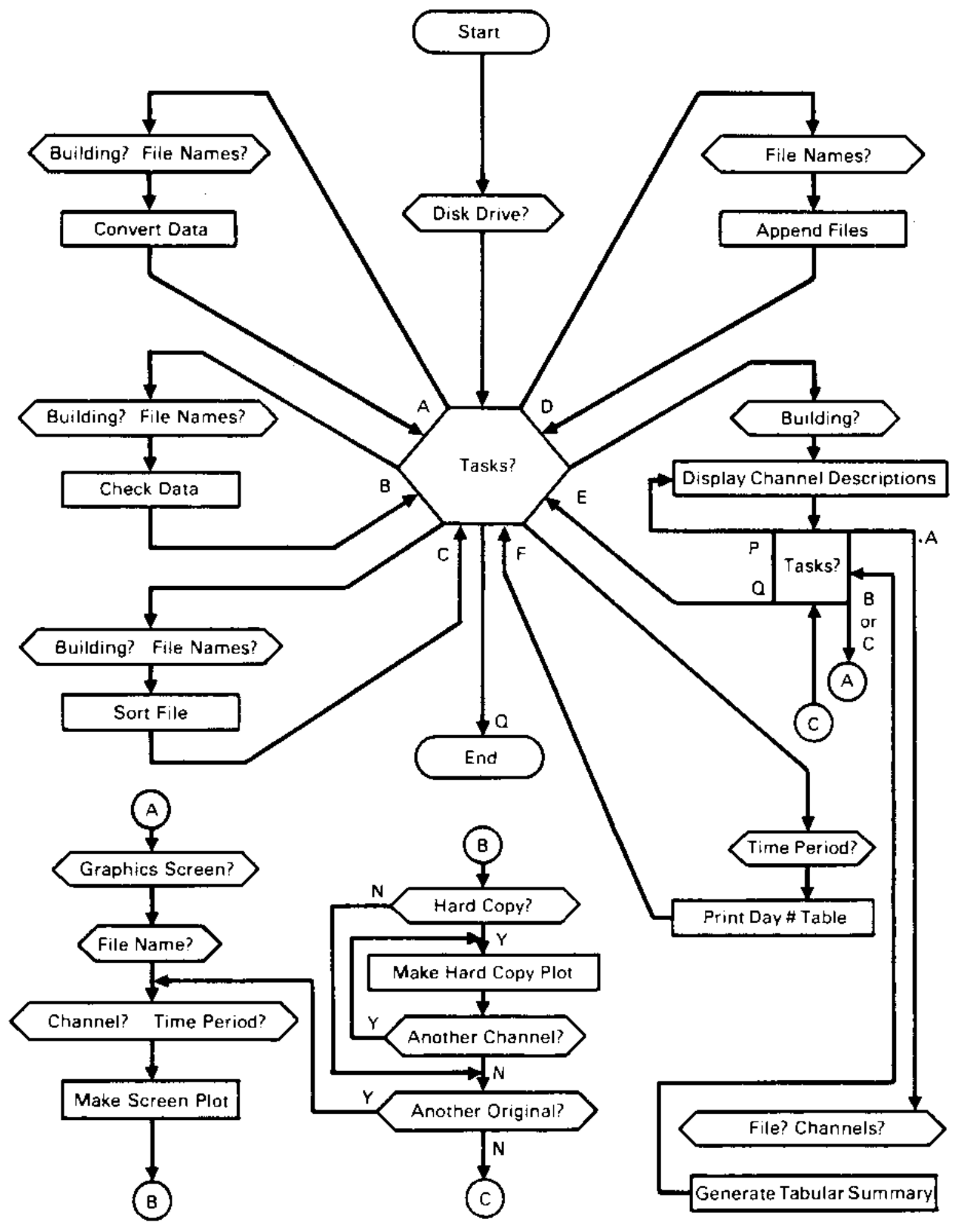

FIGURE 1. TRANZ Program Flow Diagram 


\subsection{PROGRAM CHARACTERISTICS}

\subsection{RUNT IME REQUIREMENTS}

Before running TRANZ, check the program disk directory to make sure both TRANZ. EXE and BASRUN.EXE are inciuded. The BASRUN.EXE fite is required for the proper initialization of the compiled program. If both files are there, start the program by entering 'TRANZ' after a system prompt. To initialize the computer and start DOS, the user must have a system disk with the proper 'AUTOEXEC.BAT' file containing commands that are automatically executed when the system is initialized (an important process for the printer interface). If the user is unfamiliar with DOS, check the DOS manual and the printer manual for the proper 'AUTUEXEC.BAT' file. To initialize the system, place the disk in drive 'A:' while simultaneously pressing 'Ctrl', 'Alt', and 'Del'. If the computer is turned off, simply place the disk in drive 'A:' and turn the power on.

\subsection{PROGRAM STRUCTURE}

The first prompt given by the program is as follows:

ENTER DISK ORIVE FOR BUILDING DATA FILES (A:, B:, etC.)

$$
\text { DISK MUST CONTAIN '.DAT' AND '.PAR' FILES? }
$$

After entering the drive specification ('A:' or 'B:'), which tells where the file disk will be located, the program's main menu is displayed. Table 1 gives the six main routines for TRANZ.

To choose a routine, press the corresponding key (see Table 1). The first four routines ('A' through ' $D$ ') prepare the file so that it can be summarized using the fifth routine ('E'). Not every routine, however, must be used in all cases. Al1 routines, except the summary routine, perform the desired function once for one building and one file, and they automatically return the user to the main menu. The summary routine has its own menu (see Section 7). Once the user enters the summary routine, summary work must be done for the same 


\section{TABLE 1. Example of Main Menu}

$\begin{array}{ll}\frac{\text { Key }}{\text { A }} & \begin{array}{l}\text { Convert raw data to an engineering (ASCII) } \\ \text { file }\end{array} \\ \text { B } & \text { Check engineering data for reasonableness } \\ \text { C } & \text { Sort an engineering file chronologically } \\ \text { D } & \text { Append two sorted engineering files } \\ \text { E } & \begin{array}{l}\text { Summarize an engineering file and present } \\ \text { results }\end{array} \\ \text { F Create table of day, numbers, and } \\ \text { corresponding dates }\end{array}$

PRESS DESIRED KEY

building. There is no limit, however, to the number of files used for that building while in the routine. To initialize a new building, simply exit to the main menu and reenter the summary routine.

\subsection{DISK DRIVE SPECIFICATIDN}

The first prompt the user will see after executing TRANZ will ask for the disk drive where the files are to be located. The user has three choices:

1. For a Single Drive System: Enter 'A:'. Remove the prograln disk and replace with a disk containing the files. If the program disk is removed, the computer will ask for a system disk if a runtime error occurs or if the user terminates the program. This should cause little problem.

2. For a Double Drive System: Have the program disk in drive 'A:' and the files in drive 'B:', since the computer will look for a system disk in drive 'A:' when the program terminates. The file disk may be 
changed during execution as long as the red 'busy' light for the drive is not $1 \mathrm{it}$. The new disk must have all the files necessary for the given operation.

3. For a Hard Disk: The program TRANZ.EXE (with BASRUN.EXE) and/or the building and data files may also be stored on a hard disk, usually specified as 'D:'.

\subsection{BUILDING AND FILE NAMES}

As al ready noted, each routine prompts for a building name. This name is used with the '.DAT' and '.PAR' extensions to locate these two files (i.e., generally 'building.DAT' and 'building.PAR'). These two files contain information about channel status, description, calibration factors, units, and maximum values; thus they are crucial to proper program operation. These two files are created by another BASIC program for the IBM PC . This program, called PROGRAM2.BAS (and the compiled version, DIAL.EXE), was also developed by PNL for ELCAP. Example '.DAT' and '.PAR' files are shown in Tables A.1 and A.2 of Appendix A.

Several problems may occur with incorrect building name inputs. Note that the default record length is nine. If the screen shows 'RECORD LENGTH 9 ' after prompting for a building name, an incorrect or missing building name was probably entered. Reinitialize the program and start again.

Spelling is important. If a misspelled building name is entered, a blank '.DAT' file and '.PAR' file will be created under that name. If file names are misspelied, a disk error will result in most cases, and execution will be stopped. A typical error message is 'File not found at address XXXX:YYYYY', where $X X X X$ and YYYY are four digit hexadecimal numbers.

The usual form for raw data file names is 'building.ddd', where 'building' is the building name and 'ddd' is the date of collection (e.g., for July 2, ddd $\left.=' 702^{\prime}\right)$. A convenient way to label ASCII engineering files is 'buildENGR.ddd', where 'build' is the first four letters of the building 
name. Numbers can be used instead of names; e.g., use only the numbers when naming engineering files (7777ENGR.ddd).

If the file name to be created is the same as a file that already exists on the file disk, two things can happen. If that file is already open (i.e., being used), the following runtime error will occur: 'File already open at address $X X X X: Y Y Y Y^{\prime}$. Program execution will be terminated. If the file is not open, the engineering file being created will be appended (in the same form as if it were given a new name) to the end of the existing file, whatever it may be. This cannot be done as a means of appending without using the append routine because time overlap is not removed, and index numbers are not changed. If the engineering file is appended to a compressed data file, both the compressed data and the engineering data are rendered useless and cannot be accessed. With the sort routine, the user has the option to name the sorted file the same name as the unsorted file, but the unsorted file will be deleted. One should not, however, use the name of any other existing file.

\subsection{INKEYS AND USER INPUTS}

The pauses in the program suspend operation until the user enters a character from the keyboard. The message 'PRESS ANY KEY TO CONTINUE' is displayed on the screen. Nearly any key will work (except 'shift', 'control', etc.), but do not use the F1 through F10 function keys (left of the main keyboard) because they enter more than one character into the keyboard buffer. Thus, pauses after that point may be skipped because the keyboard buffer already contains a character, and the program does not look for another character from the keyboard. For this reason, do not type into the keyboard buffer during program execution.

\subsection{EXAMINING FILES}

If questionable program results occur during program execution, look at the current files using the DOS 'TYPE' command after a DOS-system prompt. To obtain a DOS-system prompt the user must first terminate operation of the program. The format for the command is as follows: 'TYPE device:filename.extension'. The 'device' is the drive letter where the file 
can be found. Punctuation is important. After the command is entered, the file will be printed on the screen. To temporarily stop the type command, press the 'Num Lock' key while holding the 'control' key down (i.e., controlNum Lock). To continue, press any other key. To terminate the type command, simply use 'control-Break'.

To get a hard copy of the file while using the DOS 'TYPE' command, press control-PrtSc (i.e., Print Screen) before entering the command and after the command is complete. With this method, the user can also produce a hard copy of small sections of the data by entering the control-PrtSc to start printing at a given point and again to stop. For any printer to function properly, the computer must be initialized correctly according to the printer specifications, and the printer must be 'on line'. (If correct initialization is not known, check tne printer manual.) When printing, the computer must be correctly initialized. If a hard copy of the whole file is desired, use the DOS 'COPY' command. In this case, the file is not shown on the screen. The format for this command is as follows: 'COPY device:filename.extension LPTI:'. The command sends the file directly to the line printer. 


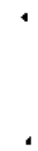

• 


\subsection{ROUTINE TO CONVERT RAW DATA TO ASCII ENGINEERING UNITS}

When raw data are obtained from the data loggers, they are stored in a file as a succession of one-byte characters. By typing the file on the screen, the user will see what looks like random characters and will probably hear several beeps from the computer. (These beeps are due to control characters in the file.) TRANZ can take the nearly incomprehensible, compressed data and properly convert it to a formatted ASCII engineering unit file only when the correct '.DAT' and '.PAR' files are used. If the wrong files are used, or if one is not current, the data conversion will not work correctly, and the resulting file will be of little use. An incorrect '.PAR' file yields an incorrect record length, and numbers will be read into the wrong category. An incorrect '.OAT' file will give improper calibration of the data. This problem can be difficult to detect because the file will look organized, and yet much or all of the data may be incorrect.

The program allows for data with any integration period to be converted, primarily to accommodate both initial 5-min integration and standard hourly integration. The integration period is determined from the '.PAR' file; again the wrong file could result in incorrect data. If the integration period is wrong, then all data will be scaled incorrectly, though relative magnitudes will be unchanged.

The routine begins by prompting the user for the building name to find the correct '.OAT' and '.PAR' files. The actual prompt is

\section{BUILDING?}

After the name is entered, the program returns the record length and prompts for the compressed file name with

\section{COMPRESSED FORMAT FILE NAME?}

Once this file name is entered, the number of channels is returned by TRANZ and the ASCII engineering file name is asked for with the prompt

\section{ASCII OUTPUT DATA FILE NAME?}


The program then proceeds to convert the compressed file to engineering units and returns to the main menu.

Once the converted file is created, either examine the file from outside the program or use the check routine to ensure that the data are reasonable. The check routine will help spot the 'out of range' values, overflow errors, and problems with the '.DAT' file. If an extreme number of errors are noted on several channels, exit the program and examine the actual file. 


\subsection{ROUTINE TO CHECK DATA REASONABLENESS}

The primary function of this routine is to check the data for values that are 'out of range'. An 'out of range' value is one that is less than zero or greater than the maximum value taken from the '.DAT' file. If the temperature data are in degrees Celsjus, an error may occur because of negative data, since below freezing temperatures are common. Because the good data range is flexible, two other errors are noted by the check routine: printing overfiows and possible bad '.DAT' file values.

Often during the conversion process, data that were originally erroneous in the logger will convert to numbers that will not fit in the 5-digit field designated for them. In this case, an overflow marker (i.e., the s sign) is printed with the oversized number. Unfortunately, the whole data field becomes offset. Thus, it is necessary to check for and to keep track of overflows as the file is being read in order to keep the data from becoming jumbled.

In addition, some of the converted data may look incorrect because of an incomplete or incorrect '.DAT' file, even though, at least in the raw data file, the data are correct. This is because the maximum value for each channe? is obtained using the maximum count value (usually 255) and two calibration factors in the '.DAT' file. The maximum value is calculated from the equation

$$
\operatorname{ZMAX}(Q)=\operatorname{VAL}(C L 1 \$) * \operatorname{VAL}(M V \$)+\operatorname{VAL}(C L 2 \$)
$$

where $Z$ MAX $(Q)=$ maximum value for channel $Q$

$$
\begin{aligned}
\operatorname{VAL}(C L 1 \$) & =\text { calibration constant number one } \\
V A L(M V \$) & =\text { maximum number of counts (from '.DAT' file) } \\
\operatorname{VAL}(C L 2 \$) & =\text { calibration constant number two. }
\end{aligned}
$$

If any of these values is incorrect, the range by which values are checked will be incorrect. For this reason, maximum values that are obviously incorrect (i.e., $\leq 0)$ are noted.

This routine also begins by prompting for the building name with

$$
\text { BUILDING? }
$$


Then, after returning the record length, the program will continue by prompting for the name of the file to be checked with

NAME OF ENGINEERING FILE TO BE CHECKED?

Once the file name has been entered, the program will prompt for the reasonable range for the temperature data with

\section{MINIMUM VALUE FOR TEMPERATURE DATA? \\ MAXIMUM VALUE FOR TEMPERATURE DATA?}

If the maximum value is greater than the minimum value, if the values are equal, or if no range is entered, the default values are set to $-50^{\circ}$ for the minimum and $60^{\circ}$ for the maximum (Celsius temperature range). This prompt allows a switch to kelvin if desired. After this information has been entered, TRANZ asks whether or not a hard copy of the check results is desired with

DO YOU WANT A HARD COPY OF THE RESULTS ( $Y$ Or $N$ )?

The program then proceeds to check the given data.

The output begins by giving the time period that the data encompasses. Then the error summary output is presented as follows: The kind of error being summarized is printed first. Then 'out of range' values, overflow errors, and '.DAT' file warnings are summarized, respectively. For each channel with an 'out of range' value or an overflow, the channel description and the number of errors for that channel are displayed with the total number of 'out of range' values or overflows. For channels with a maximum value (from the '.DAT' file) $\leq 0$, the channel description is noted, and the total number of warnings is stated. If a channel description of ' $\star \star$ NO LABEL $\star \star \prime \prime$ is given, the program probably tried to read nonexistent values at the end of each record, and the message should be of no consequence. If other warnings occur, examine the '.DAT' file or check the parameters with PROGRAM2.BAS or DIAL.EXE. A hard copy of the error summary is optional (an example error sumnary is shown in Table A.7). 


\subsection{ROUTINE TO SORT A FILE CHRONOLOGICALLY}

Data dumped from the logger are sequential, but the real time order of the records may not be perfectly chronological because of the logger memory configuration. Once data enters memory, it does not move; but when memory is ful1, the earliest data in memory are replaced with new data. Therefore, even though the data are in order, the earliest time may not be at the beginning of memory block. In most cases, the earliest time is somewhere in the middle of the file. From that point to the end of the file will be chronological, and from the beginning of the file to that point will be chronological. This routine separates the two sections and rewrites them in order.

First the program searches for the earliest time by reading through the file. When determined, the record number for the earliest time is noted. Then, beginning at that record, the file is rewritten in a new file until the end of the file is reached. Subsequently, the beginning portion of the file is rewritten in the same new file after the earlier data. As the new file is created, the records are renumbered. If any power outages are detected (i.e., a day number $(100)$, then those records are noted and are given new 'day numbers' and 'seconds since midnight' data in the sorted file. If all the data are for a power outage, that data are sorted; however, the days and times are not changed because there is no reference from which the values can be obtained.

The routine begins with the standard prompt for the building name:

\section{BUILDING?}

After returning the record length, the program then gives the following two prompts in succession:

NAME OF ENGINEERING FILE TO BE SORTED?

ENTER NAME FOR NEW SORTED FILE:

(SAME AS ABOVE FOR WRITE-OVER)?

Once the file names have been entered, TRANZ begins the sorting process. Messages noting what the prograri is doing are displayed along with the number of power outages. If the file is already sorted, the program gives the user 
the option to resave the file with the corrected 'day numbers' and 'seconds since midnight' (for files with power outages) with the following prompt:

RESAVE WITH POWER OUTAGE DAYS/TIMES RESET (Y Or $N$ )?

The routine will resave the file even if no power outages were detected during the sorting procedure, if a ' $y$ ' is entered.

If the sorted file is to be given the same name as the unsorted file, the sorted file is first saved under a temporary name. When complete, the unsorted file is deleted, and the sorted file is given its name. Thus, the disk must still have enough space to hold the remporary file before the sort begins. 


\subsection{ROUTINE FOR APPENDING FILES}

This routine will join two files, creating a third file and eliminating any duplicate data. In this way, several files may be appended, two at a time. The program, however, can only handle up to 999 records per file. In this routine, TRANZ gives the following three prompts for file names before beginning the append:

NAME OF FIRST FILE?

NAME OF FILE TO APPEND?

NAME FOR NEWLY APPENDED OUTPUT FILE?

The routine first determines the earliest and latest time for each of the two files to be appended. To be done correctly, both files must already be sorted. The order in which the first two files are entered has no bearing on the appending process. Then the configuration of the two files is determined. If the files overlap (Figure 2a), then the program proceeds to append. If one file is included in the other (Figure $2 b$ ), the message

TIME PERIDD FOR filel INCLUDES ALL OF file?

is given, and the program returns to the main menu. If the files include the same time period (Figure $2 c$ ), the message

FILES filel AND file2 INCLUDE the SAME TIME PERIOD

is displayed, and the program returns to the main menu. In these two cases the files are not appended. If the files do not overlap (Figure 2d), the message

FILES filel AND file2 INCLUDE TOTALLY DIFFERENT TIME PERIODS FILES MAY BE DISJOINT

is given, and the user has the option to continue the append or to abort. During the actual append process, the file with the earliest time (e.g., file $A$ ) is simply rewritten under the append file name. Then the file with the latest time (e.g., file B) is rewritten at the end of the new appended file, beginning with the first record in file $B$ after the last time in file $A$. The records from file $B$ are renumbered to obtain unduplicated sequential indexes. 


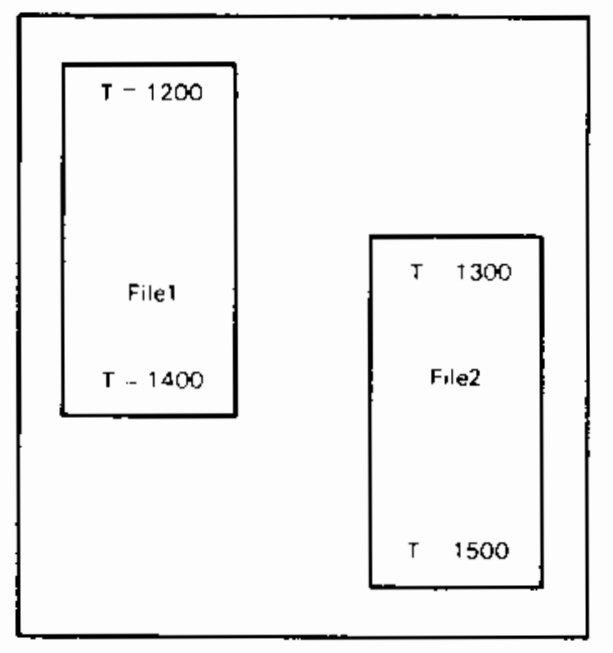

(a)

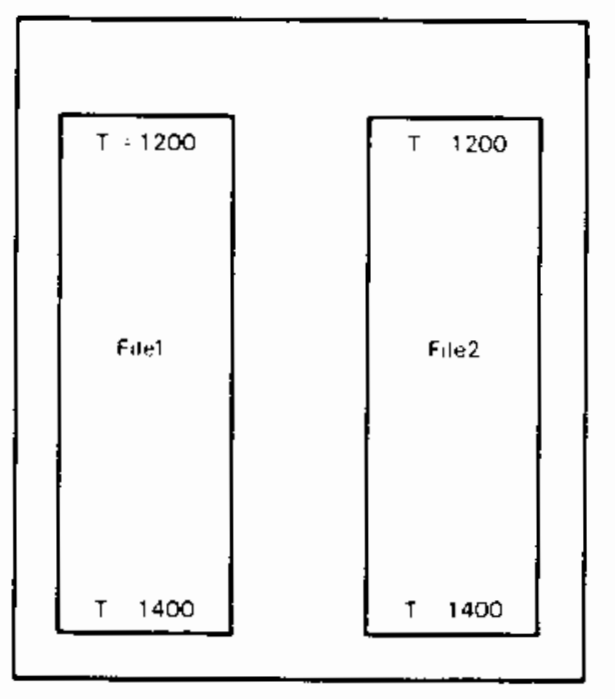

Note T Time

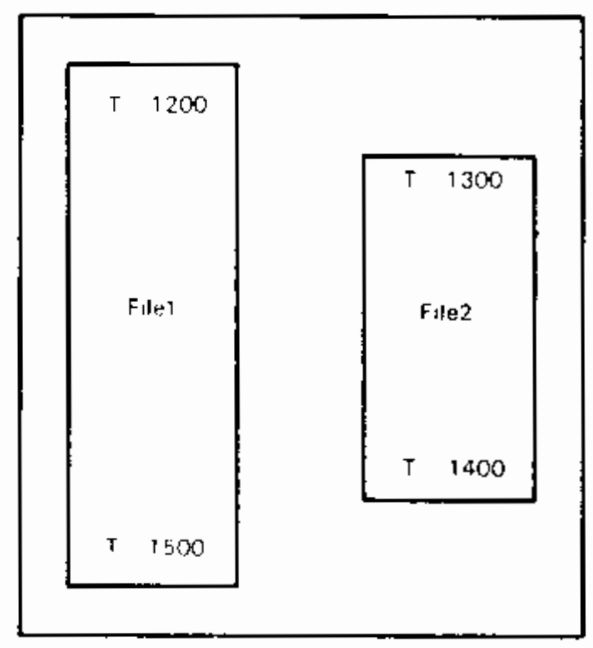

(b)

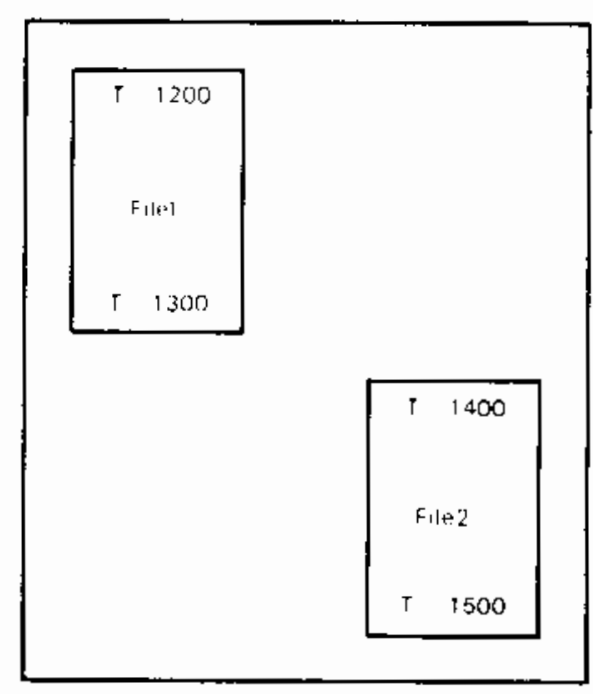

(d)

FIGURE 2. Configurations for Files to be Appended

(a) Overlapping Files

(b) One File Included Within Another File

(c) Files Include Same Time Period

(d) Files Do Not Overlap 


\subsection{ROUTINE TO SUMMAR IZE DATA}

This routine is divided into two major sections: tabular summaries and graphical summaries. Though the menu (Table 2) has three execution options ( $A$, $B$, and $C$ ), both plotting routines use the same section of code, and a flag determines which of the plots is created. After choosing the summary routine, TRANZ prompts for the building name with

\section{BUILDING?}

When that is entered, the record length is returned and the program prompts with

DO YOU WANT A HARD COPY OF 'ON CHANNEL' DESCRIPTIONS ( $Y / N)$ ?

When the question is answered, the progran proceeds to display the 'ON CHANNEL' descriptions in groups of ten. As the program states, the user can return to the 'ON CHANNEL' descriptions at nearly any pause in the summary routine by entering a ' $P$ '. TRANZ then displays the following summary menu:

TABLE 2. Example of Summary Menu

\begin{tabular}{|c|c|}
\hline Key & Choice \\
\hline A & $\begin{array}{l}\text { Tabular Summaries (Max, Min, Avg, Std Dev, } \\
\text { Total) }\end{array}$ \\
\hline B & Scatter Plot of Usage Data \\
\hline C & Point-to-Point Plot of Usage Data \\
\hline$p$ & Display 'On Channel' Descriptions \\
\hline$Q$ & QUIT $\star \star \star \star$ (Return to Main Menu) \\
\hline & PRESS DESIRED KEY \\
\hline
\end{tabular}

\subsection{TABULAR SUMMARIES}

When the tabular summary (choice ' $A$ ') is chosen, TRANz first prompts for the file name with 


\section{NAME OF ENGINEERING FILE TO BE SUMMARIZED}

(DO NOT ENTER 'P' FOR OESCRIPTIONS)?

All files to be summarized must be sorted, so the routine will work properly. If ' $P$ ' is entered at this point, it will be taken as the file name. Next, the progran will ask

\section{DO YOU WANT A HARO COPY OF THE TABLE ( $Y$ Or $N$ )?}

This input determines whether or not the resulting summary table is sent to the printer. After this information is received, TRANZ prompts with

NUMBER OF CHANNELS TO BE SUMMARIZED AND TABULATED (1-ALL)?

By entering 'ALL', the program will automatically summarize every channel. The user may also choose a specific number of channels not to exceed the total number of 'ON CHANNELS'. If something besides 'ALL' or a number is entered, a zero is assumed for the number of channels to be summarized. Even though the program will search the file, no actual summary will be generated. If a number other than 'ALL' is entered, the program will prompt with

\section{ENTER 'ON CHANNEL' NUMBERS AS GIVEN IN THE TABLE.} (OR 'P' FOR DESCRIPTION DISPLAY)?

Choosing specific 'ON CHANNELS' may be desirable when making comparisons because the channels can be summarized in any order. If an 'ON CHANNEL' number is chosen that does not exist, the program assigns ' $* \star$ NO LABEL $\star \star \prime \prime$ to that 'ON CHANNEL' description. If an incorrect 'ON CHANNEL' number is accidentalty entered, the process can be reinitialized by entering ' $P$ '.

The tabular summary yields five types of information for each ' $O N$ CHANNEL':

1. minimum value for the channe?

2. maximum value for the channel

3. average value for the channel

4. standard deviation for all channel values

5. total of all channel values.

As the program reads through each channel, it keeps a running tally of the sum of the channel vaives, the sum of the square of the channel values, and the 
number of values. The program simultaneously keeps track of the minimum and maximum for the channel. The standard deviation is calculated using the following equation:

$$
\operatorname{SOEV}=\operatorname{SQR}\left(\left(x_{i}^{2}-n * x_{\text {avg }}^{2}\right) /(n-1)\right)
$$

where SDEV = the standard deviation for the channel $i$

$S Q R=$ the square root function

$x_{j}=$ an individual value for the channel $i$

$n=$ the number of values for the channel $i$

$x_{a v g}=$ the average value for the channel $i$.

If the argument of the square root function is less than zero (negative), then the argument is set to zero. When an overflow is encountered, the maximum, minimum, and average will be 99999. An example of channel summary output can be found in Table A.9 of Appendix A.

\subsection{GRAPHICAL SUMMARIES}

When trying to understand trends in the data, the graphical summaries are the most usefui tool. Files to be plotted must be previously sorted in order for the graphical routine to work correctly.

When entering the routine, the program asks if the user is using a graphics capable screen with the prompt

DO YOU HAVE A GRAPHICS CAPABLE SCREEN $(Y / N)$ ?

This option allows those users who have a plotter but no graphics screen to generate hard copy plots. If a graphics screen is not being used and a ' $y$ ' is entered, the error message 'Device unavailable at XXXX:YYYYY' will appear, and program execution will be terminated. The next prompt that appears in the program is

NAME OF SORTED FILE TO BE PLOTTED?

When the file name is received, TRANZ asks for the 'ON CHANNEL' that is to be plotted with

ON CHANNEL NUMBER FOR PLOT TO BE CREATED? 
If the number is not known, the user can go to the 'ON CHANNEL' descriptions by entering ' $P$ '. If an on 'ON CHANNEL' number is given that does not exist, the program tells the user that no data exists or that all quantities have values of zero. Next, TRANZ prompts for the time period that the plot will include according to the following format:

\author{
ELCAP DAY 1 = JANUARY 1,1981 \\ ELCAP DAY NUMBER AT WHICH PLOT WILL BEGIN ('ALL' FOR FILE)? \\ TIME (IN SECONDS) FOR THE ABOVE DAY? \\ ELCAP DAY NUMBER AT WHICH PLOT WILL END? \\ TIME (IN SECONDS) FOR THE ABOVE DAY?
}

Entering 'ALL' after the first prompt will skip the other prompts and will automatically plot all the data in the file. If nothing is entered for a prompt, then a zero value is assigned. If any other word besides 'ALL' is entered for the first prompt, zero is assigned. Obviously, if the time period that the data encompasses is not known, start with the 'ALL' option. Once the entire file is plotted, the user can focus on smaller portions of the tineline.

Once the plot has been generated on the screen, it remains untit the user enters a character from the keyboard. When the character is received, TRANZ prompts with

DO YOU WANT A HARD COPY OF THE PLOT $(Y / N)$ ?

If an ' $N$ ' is entered, the program branches around the hard copy plotting section and asks whether another plot from the same file is desired. If $a$ ' $Y$ ' is entered, the program prompts with

DO YOU HAVE AN HP PLOTTER? ( $A=7475 \mathrm{~A}, \mathrm{~B}=7470 \mathrm{~A}, \mathrm{~N}=$ NONE)

The program was designed only for the HP 7470A and the HP 7475A plotters. It may, however, be possible to use the program with other plotters based on the HP-GL plotter language used in this program. Some experimentation will probably be required. If an ' $N$ ' is entered, the program jumps to the end of the routine and asks whether another plot from the same file is desired. If either 'A' or ' $B$ ' is entered, the program will continue with the prompts 


\section{LOAD PAPER FOR PLOT AND PREPARE PLOTTER}

PRESS ANY KEY TO CONTINUE

This pause allows the user to get the paper loaded correctly and to make certain that the plotter is properly connected to the IBM PC. This pause is especially useful for computers with only one communications port, where the printer may have to be disconnected in order to connect the plotter. When the program continues, it prompts for the comnunications port with COMMUNICATIONS PORT NUMBER (COM1, COM2)?

If anything other than the two specified inputs (i.e., COM1, COM2) is entered, the error message 'Device unavailable at $X X X X: Y Y Y Y$ ' is displayed, and program execution is terminated. This option allows for computers that may have more than one communications port to choose from, eliminating the need to switch cables in the back of the machine.

If the plotter specified is the HP 7475A, then the program will prompt for the paper size with

$$
\text { PAPER SIZE FOR PLOT? }(1=11 \times 17,2=8.5 \times 11) ?
$$

Though ' 1 ' and ' 2 ' are specified as inputs, any whole number $<1$ will set the 11- $x$ 17-in. paper size, and any other whole number will set the $8.5-\times 11-i n$. paper size.

After the plot is finished, TRANZ displays the message WANT ANOTHER ORIGINAL. OF THE SAME PLOT $(Y / N)$ ?

If a ' $Y$ ' is entered, then the same plot will be generated again, beginning with the pause for loading the paper. The computer may show this prompt before the plotter is actually finished plotting, so the user should wait until the plot is complete before proceeding. If an ' $N$ ' is entered, then the program prompts with

\section{PLOT ANOTHER CHANNEL FROM THE SAME FILE ( $Y$ or $N)$ ?}

If $a$ ' $^{\prime}$ ' is entered, the routine starts again at the prompt for the 'ON CHANNEL' to be plotted. The second plot that is generated will be the same 
type as the first (i.e., scatter or point-to-point). If an ' $N$ ' is entered, then the program returns to the summary menu.

Using the user-defined limits, the program gathers the data. Then after determining the maximum and minimum values on both axes, the program sets the configuration and increments for the axes. The horizontal time axis will always round to the next lowest and the next highest day when setting the axis length, although oniy data for the chosen time period is plotted. The vertical axis always ranges from the minimum value (or zero, whichever is lower) to the maximum value. Negative data will be plotted correctly. If a power outage gap is found in the data file, a line will connect the bounding data points on a point-to-point plot. This fact may be helpful in explaining strange data characteristics. The label and units for the vertical axis are given above the plot (to the left of the plot on the hard copies). An example of a scatter plot and a point-to-point plot are shown in Figures $A .1$ and A.2, respectively, of Appendix A. 


\subsection{ROUTINE TO CREATE A TABLE OF DAY NUMBERS AND DATES}

This routine will print a one-to-three column table of day numbers and their corresponding date. The day of the week is also included. When the routine is specified, the following prompts appear on the screen:

ELCAP DAY NUMBER TO START THE TABLE?

〈JANUARY 1, 1981=1> 〈JANUARY 1, 1982=366> 〈JANUARY 1, 1983=731>

〈JANUARY 1, 1984=1096〉 〈JANUARY 1, 1985=1462〉 〈JANUARY 1, 1986=1827〉

ELCAP OAY NUMBER TO END THE TABLE?

The user defines the 1 imits of the table using day numbers. Any time period since January 1, 1981, can be tabulated. Every day number for the period is printed for the user's ease in determining the corresponding date. Day numbers and dates are printed both on the screen and on the printer. An example of the output for this routine is given in Table A.10 in Appendix A. 

APPENDIX A

SAMPLE FILES AND PROGRAM OUTPUT 


\section{SAMPLE FILES AND PROGRAM OUTPUT}

Several files and printed program outputs have been included in this appendix to show the file types under TRANZ. The building name has been changed to 'BUILDING' to ensure anonimity.

The '.DAT' file (Table A.1) is made up of 112 records (corresponding to the maximum number of channels: 48 digital and 64 analog), each with a length of 54 characters. The field is divided into six sections: the title, calibration factor one (multiplier), calibration factor two (offset), units, accuracy $\left({ }^{*}\right.$ ), and maximum counts. The file is used for identification of channels and data conversion. This file [along with the '.PAR file (see Table A.2)] is created using the program PROGRAM.BAS or DIAL.EXE. These programs were developed for the End-Use Load and Conservation Assessment Program (ELCAP) by Pacific Northwest Laboratory (PNL).

The '.PAR' file is composed of 239 records, each with a length of four characters. The various records contain information on such topics as channel status and integration period.

The first data file (Table A.3) is 'BUILENGR.831'. This file shows the form of the data just after it has been converted, al though the file has been shortened for easy display. The 'ON CHANNELS' begin in column seven. Column one is the index, column two is the check sum, column three is the record length, and column six is the wind direction. Columns four and five are particularly important to this program. Column four is the day number, and column five is the number of seconds after midnight. These six columns should contain the same type of information in all files. One can determine the on-channe1 information by correlating the data with the sequential entries in the '.DAT' file. Note that the second half of this file is power outage data. Also note that the reference column contains overflow data.

The second file (Table A.4) is "BUILSORT.831'. This file is the sorted version of the previous file. Note that none of the data has been changed, but 
TABLE A.1. Example of a '.OAT' File Used for Identification of Channels and Data Conversion

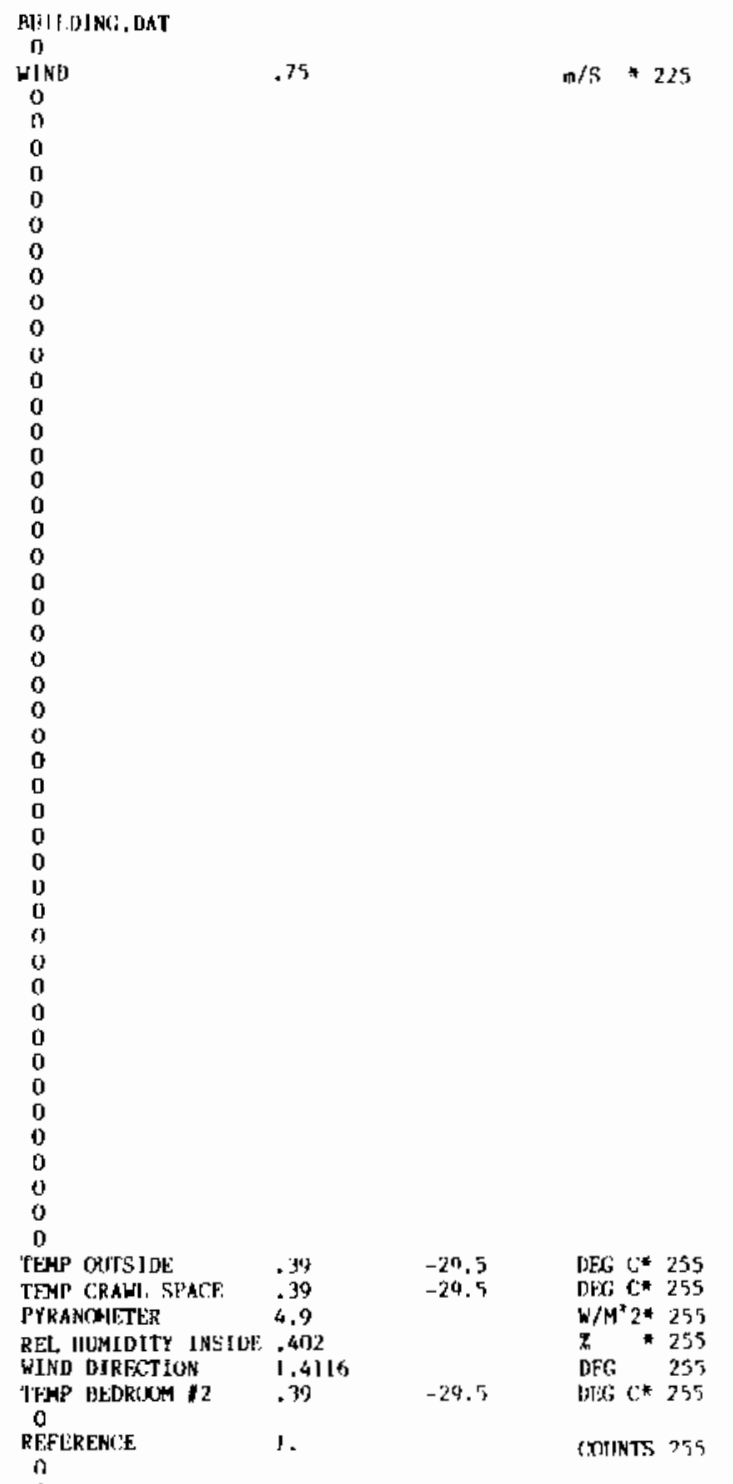

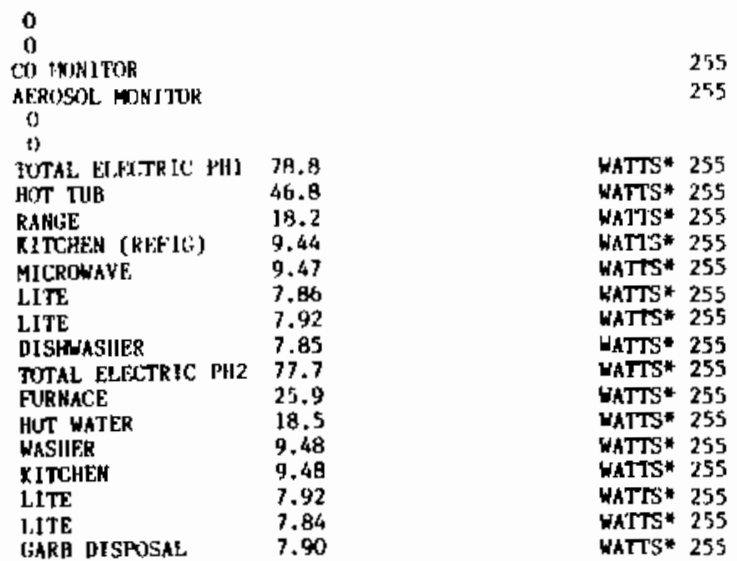

255

WATTS* 255

(1)

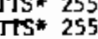

TTS* 255

(UTTS* 255

TTS* 255

WATS* 255

WATTS* 255 
TABLE A.2. Example of '.PAR' File Containing Information on Channel Status and Integration Periods

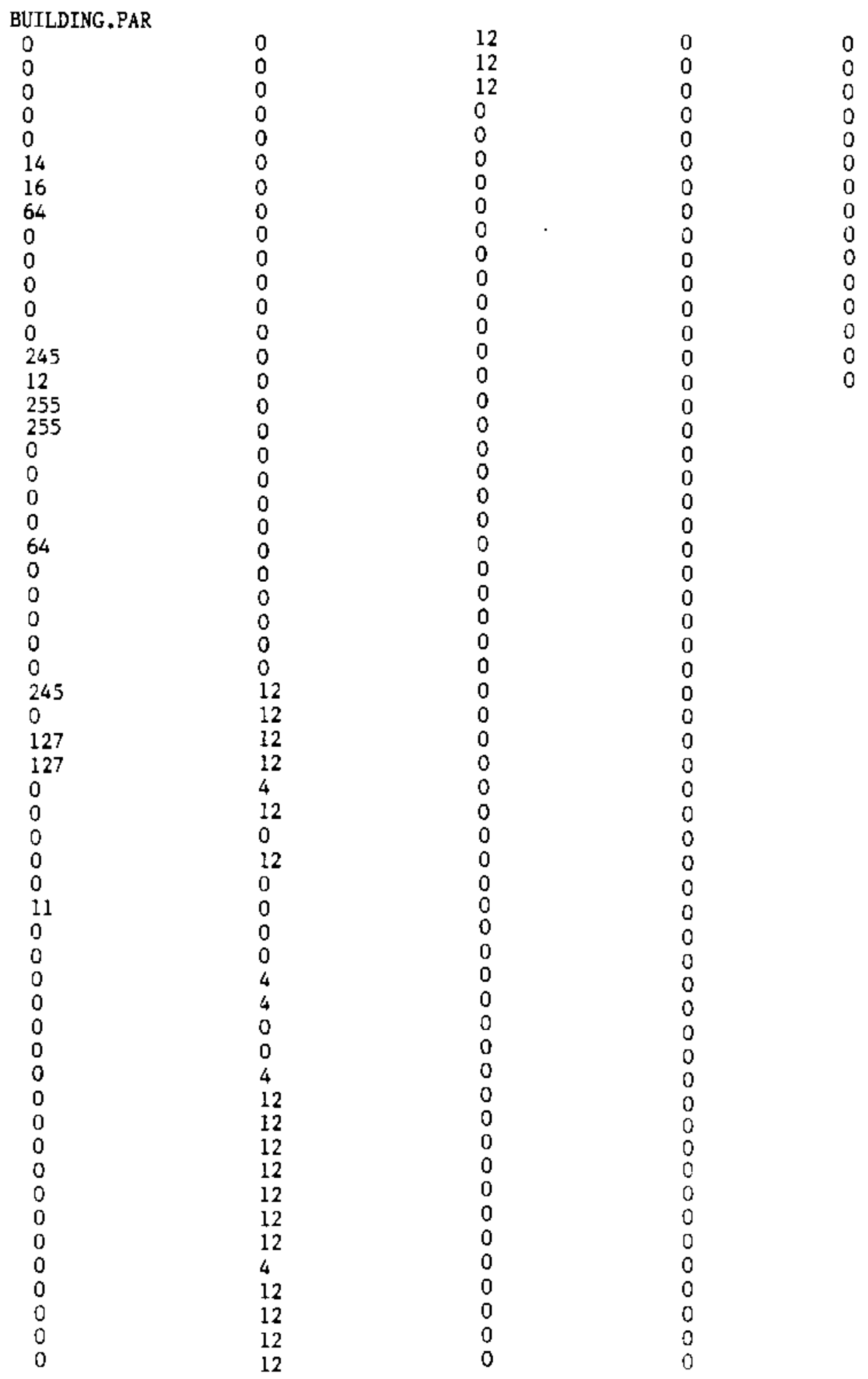

A.3 
TABLE A.3. 'BUILENGR.831' (First Data File)

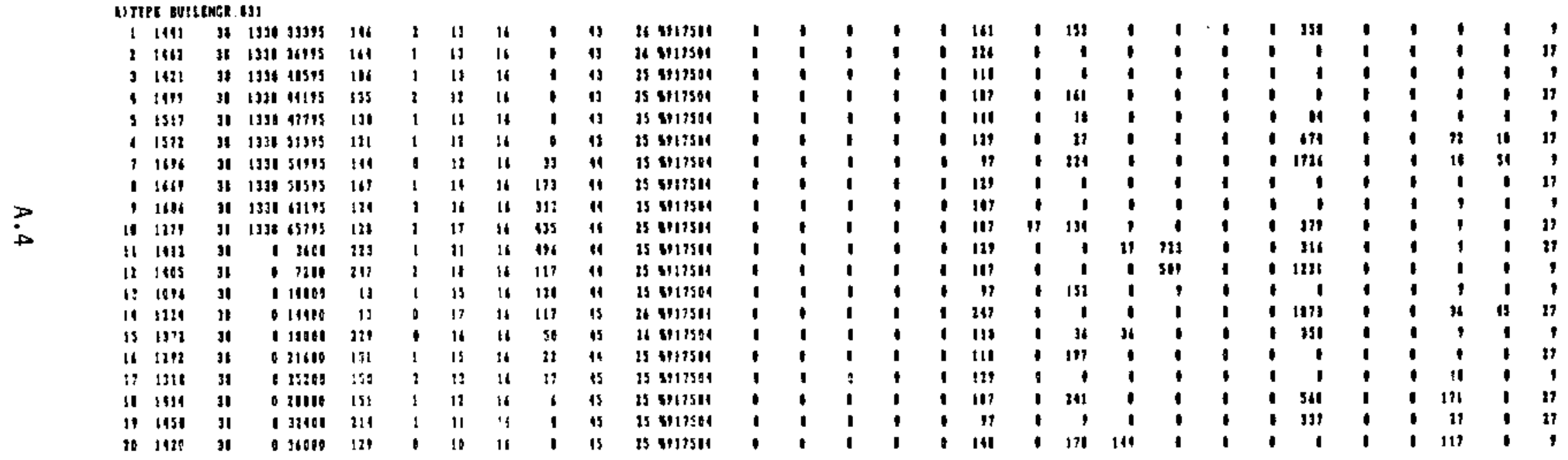


TABLE A.4. 'BUILSORT.B31' (Second Data File)

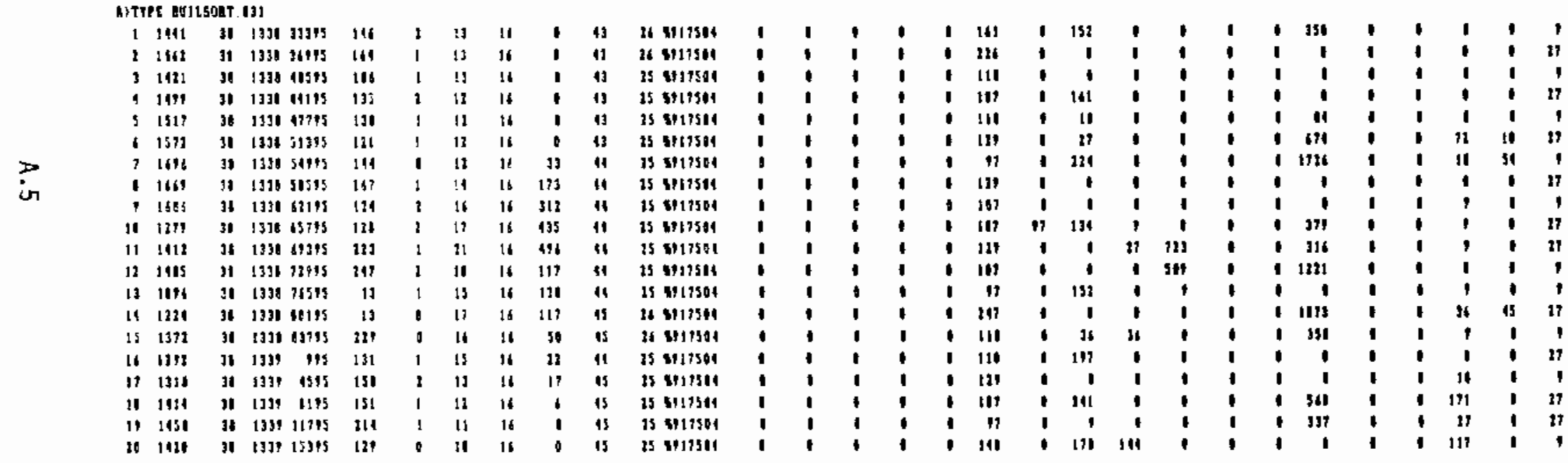


the day numbers and the seconds since midnight for the power outage have been reset. This file was used for subroutines ' $B$ ' and ' $D$ '.

The third file (Table A.5) is 'BUILDENGR.830'. This sorted engineering file contains data prior to the file 'BUILSORT.831' and was appended to that file. The appended file 'BUILAPND.831' (Table A.6) contains 35 records. Note that five repetitious records were not included a second time.

A reasonableness check summary for 'BUILSORT.B31' is given in Table A.7. The reference has 20 'out of range' values and $20^{\circ}$ overflows. A quick check of the '.DAT' file shows that neither the 'CO MONITOR' nor the 'AEROSOL MONITOR' has any calibration factors. Thus, their maximum values were computed to be zero, and they were included in the listed warnings. Also note the example of a ${ }^{1 \star \star}$ NO LABEL $\star \star '$ warning. This warning is of no consequence, unless it comes in the middle of the list. If so, the '.PAR' and '.DAT' files should be checked for errors.

The summary routine was run with the appended file 'BUILAPND.831'. A 1ist of 'ON CHANNEL' descriptions as the program would print thein is given in Table A.8. These descriptions can be checked in the '.DAT' file. Option 'A' of the summary menu produced the tabular sumnary found in Table A.9. A nanual check will verify the accuracy of the output. Option ' $B$ ' was used with the same file for the outside temperature data ('ON CHANNEL' \#2), and the scatter plot found in Figure A.1 was generated. A point-to-point plot (Figure A.2) was produced for the refrigerator ('ON CHANNEL' \#13) using option ' $C$ ' of the summary menu.

Table A.10 gives an example of the day number tables produced by the main routine ' $F$ '. 
TABLE A.5. 'BUILENGR.830' (Third Data File)

n'TTEE ENILECG. 13:

\begin{tabular}{|c|c|c|c|c|c|c|c|c|c|c|c|c|c|c|c|c|c|c|c|c|c|c|c|c|c|c|c|c|c|c|}
\hline & imi & JI & 1337 & 45715 & $\$ 14$ & 3 & 23 & 16 & $\sin$ & y & 251154 & 1 & i & I & $t$ & 1 & !3! & , & is & 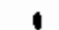 & 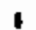 & $\mathbf{f}$ & 1 & 12 & 1 & I & & 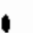 & . & 17 \\
\hline 2 & 1312 & J! & 1313 & 11395 & 151 & 1 & 14 & 17 & 116 & 10 & 11 sysuks & 1 & 1 & I & 1 & . & 17 & 11 & I & I & 1 & 1 & 1 & 1 & 1 & 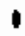 & & 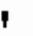 & 1 & , \\
\hline 3 & 131 & $\mathbf{t}$ & 1337 & S11195 & 181 & $\mathbf{J}$ & 37 & 17 & 563 & A1 & 21 wissot & $\mathbf{I}$ & $\mathbf{I}$ & I & 1 & 1 & 121 & $t 1$ & 1 & 91 & 1 & I & 1 & 1 & I & & & 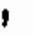 & . & 17 \\
\hline$y$ & [11] & at & {$[3 ! n$} & 7659 & 147 & 1 & 31 & II & 551 & 11 & 15 shissus & 4 & 1 & - & I & 11 & 111 & - & 134 & . & I & 1 & 1 & 1 & 1 & 1 & & 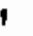 & I & 4 \\
\hline 3 & 1413 & " & 1337 & It!1s & 14: & 1 & 11 & 1t & 43 & 41 & 25 vistos & 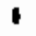 & I & 1 & 1 & 331 & 118 & I & 133 & I & 1 & 1 & 1 & 351 & 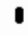 & 9 & & 1 & 1 & 1 \\
\hline I & 1537 & 3! & 1377 & 13715 & $n n$ & $t$ & 31 & II & 314 & is & at symsen & 1 & 1 & 1 & - & 166 & 14 & 1 & It & • & I & I & 1 & J3t & $\mathbf{I}$ & 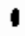 & & 7 & I & 17 \\
\hline 7 & 1546 & $\boldsymbol{H}$ & $13 \mathrm{JI}$ & 115 & mil & 3 & II & 11 & 134 & 11 & 216187394 & - & 1 & 1 & 1 & 1 & 111 & . & I & 1 & $\mathbf{I}$ & 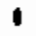 & $\mathbf{1}$ & I & । & 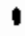 & & - & $\mathbf{1}$ & 1 \\
\hline 】 & 1911 & 11 & 1311 & tsis & 114 & 3 & 11 & 17 & I & 11 & 16517504 & i & - & 1 & - & ' & IJI & 1 & 1 & 31 & 1 & $\mathbf{I}$ & 1 & 1 & I & | & & 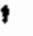 & 1 & 17 \\
\hline 1 & 1395 & 31 & 1331 & 119 & 194 & 1 & 16 & 16 & I & II & 26 sh11314 & 1 & 1 & 1 & 1 & 11 & 141 & 1 & I & $10 t$ & 1 & 1 & 1 & 1931 & $\|$ & I & & 8 & 96 & 1 \\
\hline & 1967 & 3 & 1331 & 11715 & 120 & 1 & 16 & 16 & 1 & 13 & 26519 & . & I & 1 & 1 & sst & 181 & 11 & 152 & $34 t$ & 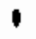 & 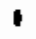 & 1 & w11 & - & 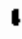 & & & 1 & 17 \\
\hline 11 & 1311 & 31 & 1331 & 15315 & 115 & 2 & is & 16 & 1 & 11 & 219117504 & 1 & 1 & I & - & 1 & 161 & ' & 1 & 319 & ! & I & 1 & - & 1 & 1 & & & 1 & ! \\
\hline 13 & 1354 & Jt & 133 & 11115 & 141 & 1 & 15 & 14 & ' & 1 & 36 w11514 & 1 & 1 & 1 & I & 1 & 117 & 1 & 171 & 15) & 1 & 1 & I & 211 & I & | & & & 1 & 1 \\
\hline ? & 1944 & 31 & IJנ38 & 21351s & 111 & 1 & 21 & 16 & 1 & 43 & If 517501 & 1 & I & 1 & I & 1 & 156 & 1 & 31 & $\mathbf{I}$ & 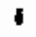 & 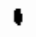 & 1 & 917 & 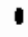 & 1 & & I & I & 11 \\
\hline 14 & 1366 & II & 1331 & 31195 & $\{1\}$ & 1 & 11 & 14 & 1 & 43 & 21 & 1 & - & t & 1 & 1 & 119 & 1 & $17 t$ & ' & I & 1 & I & - & I & | & & 1 & 1 & 1 \\
\hline & 1374 & M & 1331 & 19les & III & 1 & 13 & 16 & $p$ & 3 & "19 & 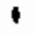 & I & 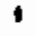 & I & I & 117 & 1 & I & 1 & 1 & : & I & I & 1 & & & 1 & I & 11 \\
\hline if & {$[14]$} & " & 131: & 33115 & 114 & 2 & 13 & if & 1 & 13 & 345 & 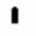 & 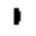 & 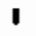 & - & 1 & $\omega 1$ & I & 151 & 1 & 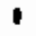 & 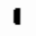 & 1 & 351 & 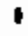 & & & , & 1 & 9 \\
\hline d? & 1481 & $3 \mathbf{3}$ & ts3t & 34195 & 114 & 1 & 13 & 16 & I & 43 & 26517504 & 1 & 1 & I & I & I & 316 & 1 & I & ' & I & 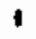 & - & 1 & 1 & I & & 1 & 1 & 11 \\
\hline & \{111 & 31 & 1331 & (1) 15 & 104 & 1 & 13 & 16 & 1 & 11 & as burst & I & 1 & 1 & 1 & 1 & 119 & I & $\mathbf{I}$ & I & 1 & 1 & 1 & 1 & I & & & 1 & I & , \\
\hline & 111" & נ1 & 1331 & 14195 & 135 & 2 & 11 & 16 & I & 13 & 255117504 & I & 1 & 1 & . & 1 & 167 & 1 & 164 & 1 & 1 & 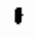 & 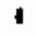 & I & & & & I & - & 17 \\
\hline & 1517 & 31 & 3930 & meps & 138 & 1 & 11 & II & 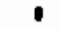 & 13 & is shitsis & 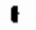 & 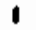 & 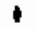 & I & I & 111 & 1 & 11 & 1 & 1 & 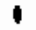 & : & II & I & & & 1 & I & \\
\hline
\end{tabular}


TABLE A.6. 'BUILAPND.831' (Appended File)

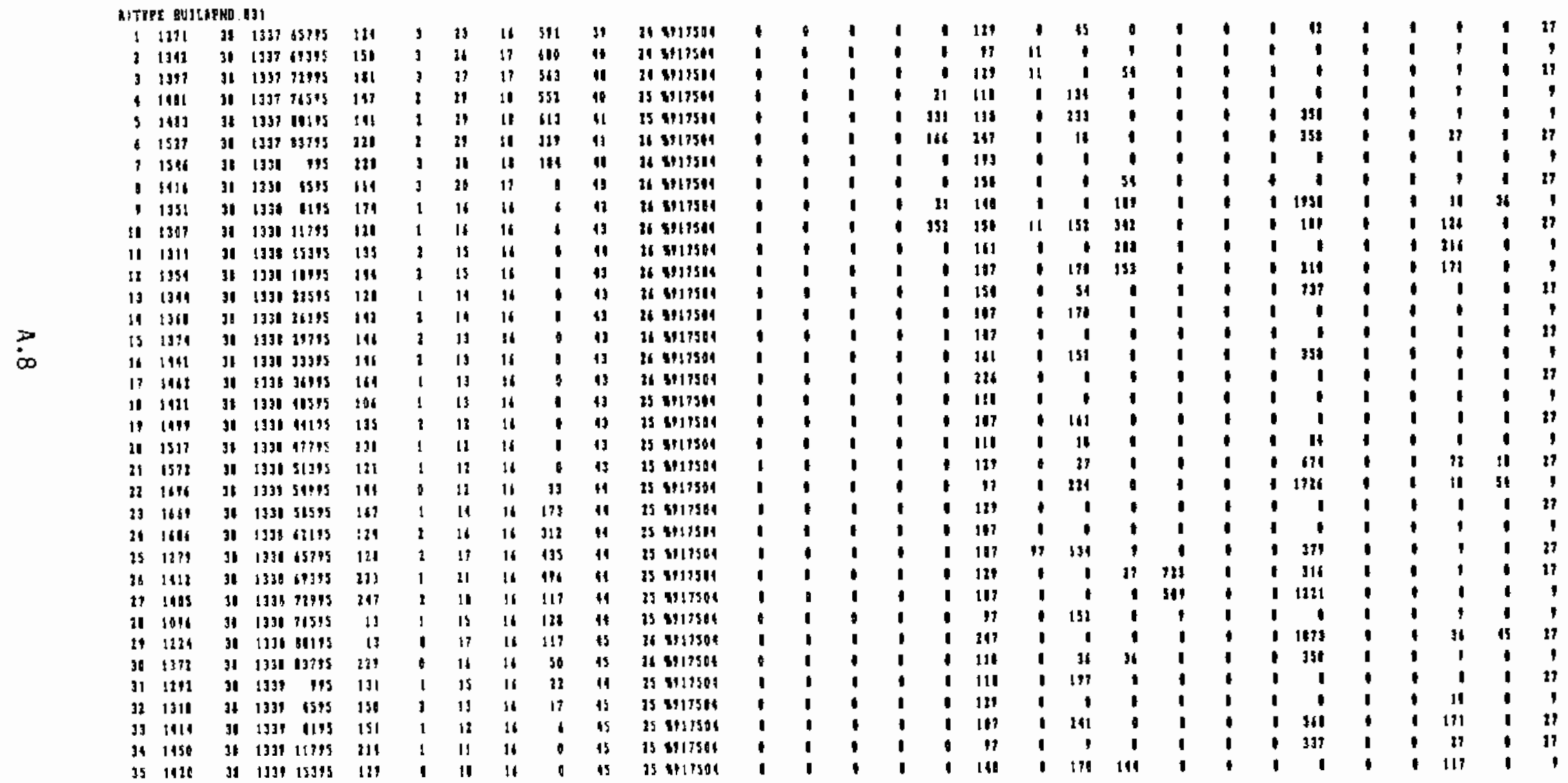


TABLE A.7. Reasonableness Check Summary for 'BUILSORT.831'

DATA SPANS THE TIME PERIOD FROM: 8/30/1984 TO $8 / 31 / 1984$ ****** SUMMARY OF ERRORS *******

$\begin{array}{lll}\text { REFERENCE } & 20 & \text { ERRORS }\end{array}$

TOTAL NUMBER OF OUT OF RANGE VALUES IS 20

**** SUMMARY OF OVERFLOWS

REFERENCE

20 OVERFLOWS

TOTAL NUMBER OF OVERFLOWS $=20$

\#***** SUMMARY OF WARNINGS

MAXIMIM VALUE FOR CO MONITOR

VLAXIMUI VALUE FOR AEROSOL MONITOR

HAXIMUIY VALUE FOR * NO LABEL **

TOTAL NUMBER OF WARNINGS IS 3
LESS THAN OR EQUAL TO ZERO

LESS THAN OR EQUAL TO ZERO

LESS THAN OR EQUAL TO ZERO 
TABLE A.8. List of 'ON CHANNEL' Descriptions

DESCRIPTIONS FOR 'ON CHANNELS' I TO 10

ON CHANNEL \# 1 WIND

ON CHANNEL \#2 TEMP OUTSIDE

ON CHANNEL \# 3 TEMP CRALL SPACE

ON CHANNEL 4 PYRANOMETER ,

ON CHANNEL \#5 REL HMMIDITY INSIDE

ON CHANNEI \#6 TESPP BEDROOM $\# 2$

ON CHANNEI, $\# 7$ REFERENCE

ON CHANNEI $\because 8 \quad$ CO MONITOR

ON CHANNEL \# 9 AEROSOL MONITOR

ON CHANNEL \# 10 TOTAL ELECTRIC PHI

DESCRIPTIONS FOR 'ON CHANNELS' 11 TO 20

ON CHANNEL \# 11 HOT TUB

ON CHANNEL \# 12 RANGE

ON CHANNEL \# 13 XITCHEN (REFIG)

ON CHANNEL \# 14 MICROWAVE

ON CHANNEL \# 15 LITE

ON CHANNEL \# 16 LITE

ON CHANNEL, \# 17 DISHWASHER

ON CHANNEI \# 18 TOTAL EIECTRIC PH2

ON CHANNEL \# 19 FURNACE

ON CHANNEL \# 20 HOT WATER

DESCRIPTIONS FOR 'ON CHANNELS' 2 I TO 25

ON CHANNEL \# 21 HASHER

ON CHANNEL 22 KITCHEN

ON CHANNEI, \#23 LITE

ON CHANNEL \# 24 LITE

ON CHANNEL \#25 GARB DISPOSAL 
TABLE A.9. Tabular Summary Produced by Option 'A' of the Summary Menu

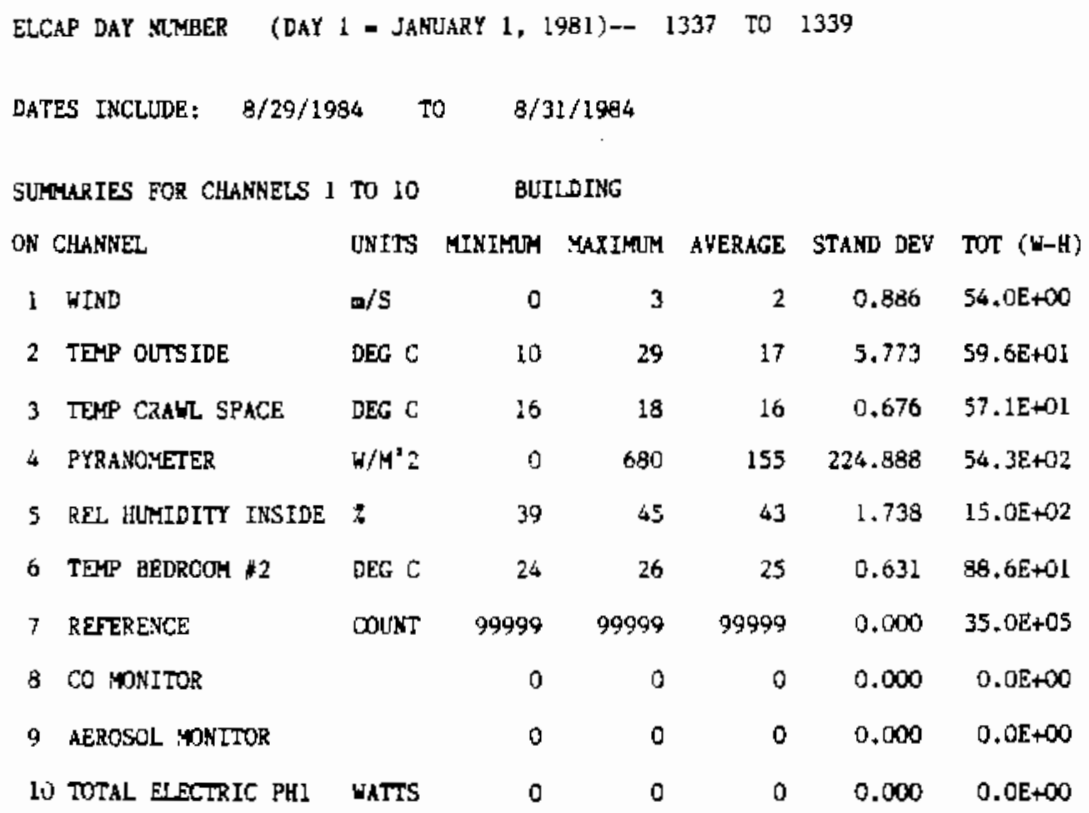

\begin{tabular}{|c|c|c|c|c|c|c|}
\hline SUMMARIES FOR CHANNELS & 17020 & & ILDTISG & & & \\
\hline ON CHANNEL & UNITS & MINIMU & YAXMMINA & AVERACE & STAND DEV & $\operatorname{TOT}(\omega-\mathrm{H})$ \\
\hline 11 HOT TUB & WATTS & 0 & 0 & 0 & 0.000 & $0.0 E+\infty$ \\
\hline 12 RANGE & HATTS & 0 & 352 & 25 & 83.880 & $89.1 E+01$ \\
\hline 13 KITCHEN (REFIC) & WATTS & 97 & 247 & 134 & 39.398 & $46.9 E+02$ \\
\hline 14 MICROWAVE & WATTS & 0 & 97 & 4 & 16.529 & $13.0 \varepsilon+01$ \\
\hline 15 LITE & WATTS & 0 & 241 & 71 & gs. 535 & $25.0 \mathrm{E}+02$ \\
\hline 16 LITE & WATTS & 0 & 342 & 37 & 83.865 & $13.1 E+02$ \\
\hline 17 DISHWASHER & WATTS & 0 & 723 & 35 & 147.318 & $12.4 E+02$ \\
\hline 18 TOTAL EIBCTRIC PH2 & HATS & 0 & 0 & 0 & 0.000 & $0.0 E+00$ \\
\hline 19 FIJRACE & WATTS & 0 & 0 & 0 & 0.000 & $0.0 E+00$ \\
\hline 20 HON SATER & WATTS & 0 & 1958 & 336 & 546.332 & $11.7 E+03$ \\
\hline
\end{tabular}

SURMARIES FOR CHANNEL I TOS BUILDTNG

UN CHANNEL

21 HASHER

22 KITCHEN

23 LITT

24 LITE

25 GARB DISPOSAL
LNITS IIINIMUM HAXIMIM AVERAGE STAND DEV TOT (W-H) $\begin{array}{llllll}\text { WATTS } & 0 & 0 & 0 & 0.000 & 0.0 \mathrm{E}+\infty\end{array}$ $\begin{array}{llllll}\text { WATYS } & 0 & 0 & 0 & 0.000 & 0.0 \mathrm{E}+\infty\end{array}$ WATTS $\quad 0 \quad 216 \quad 32 \quad 56.727 \quad 11.1 \mathrm{E}+02$ $\begin{array}{llllll}\text { WATTS } & 0 & 54 & 4 & 23.164 & 15.3 \mathrm{E}+01\end{array}$ $\begin{array}{llllll}\text { WATTS } & 9 & 27 & 18 & 9.128 & 62.1 \mathrm{E}+01\end{array}$ 


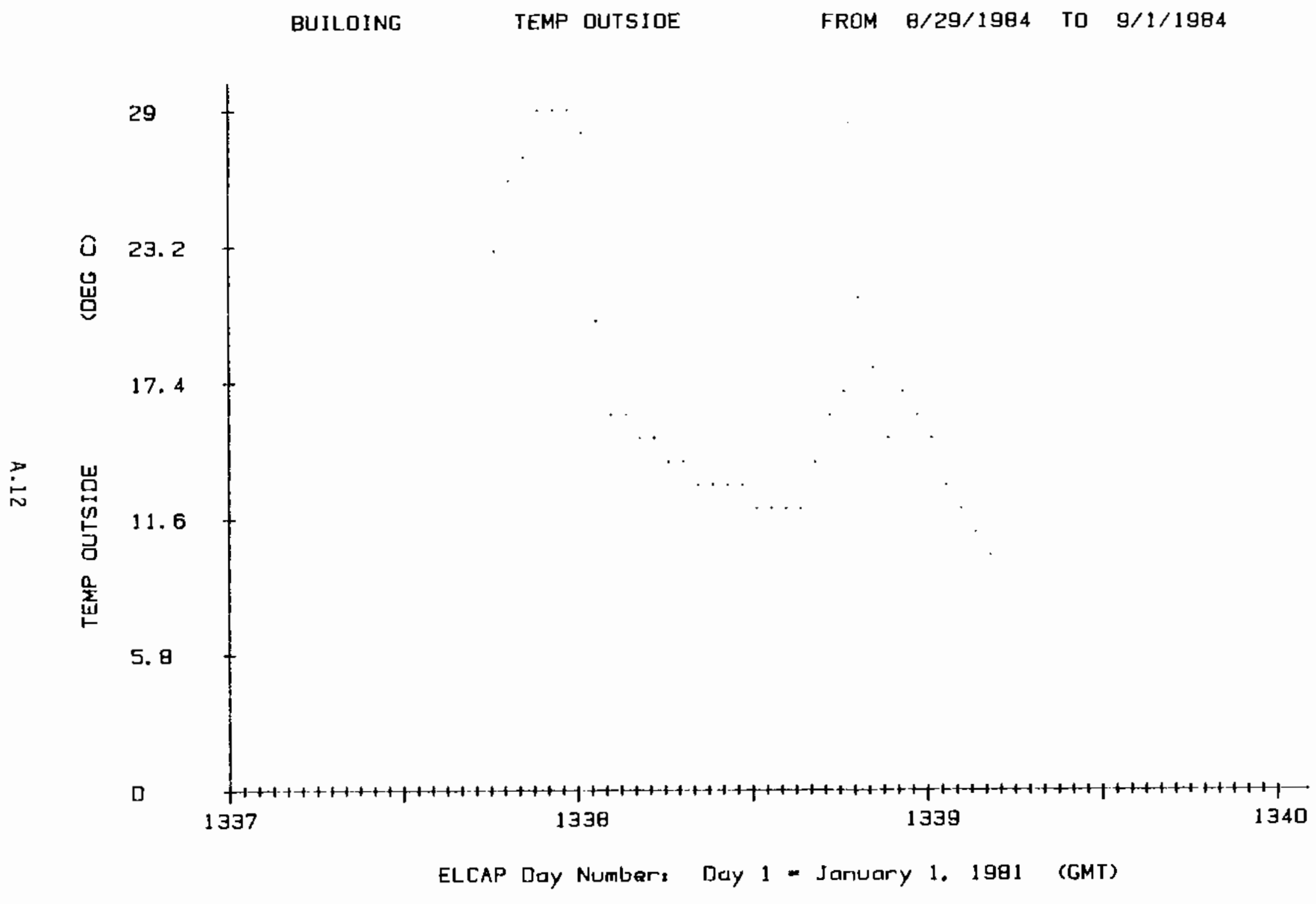

FIGURE A.1. Scatter Plot Generated by Option 'B' for Outside Temperature Data 


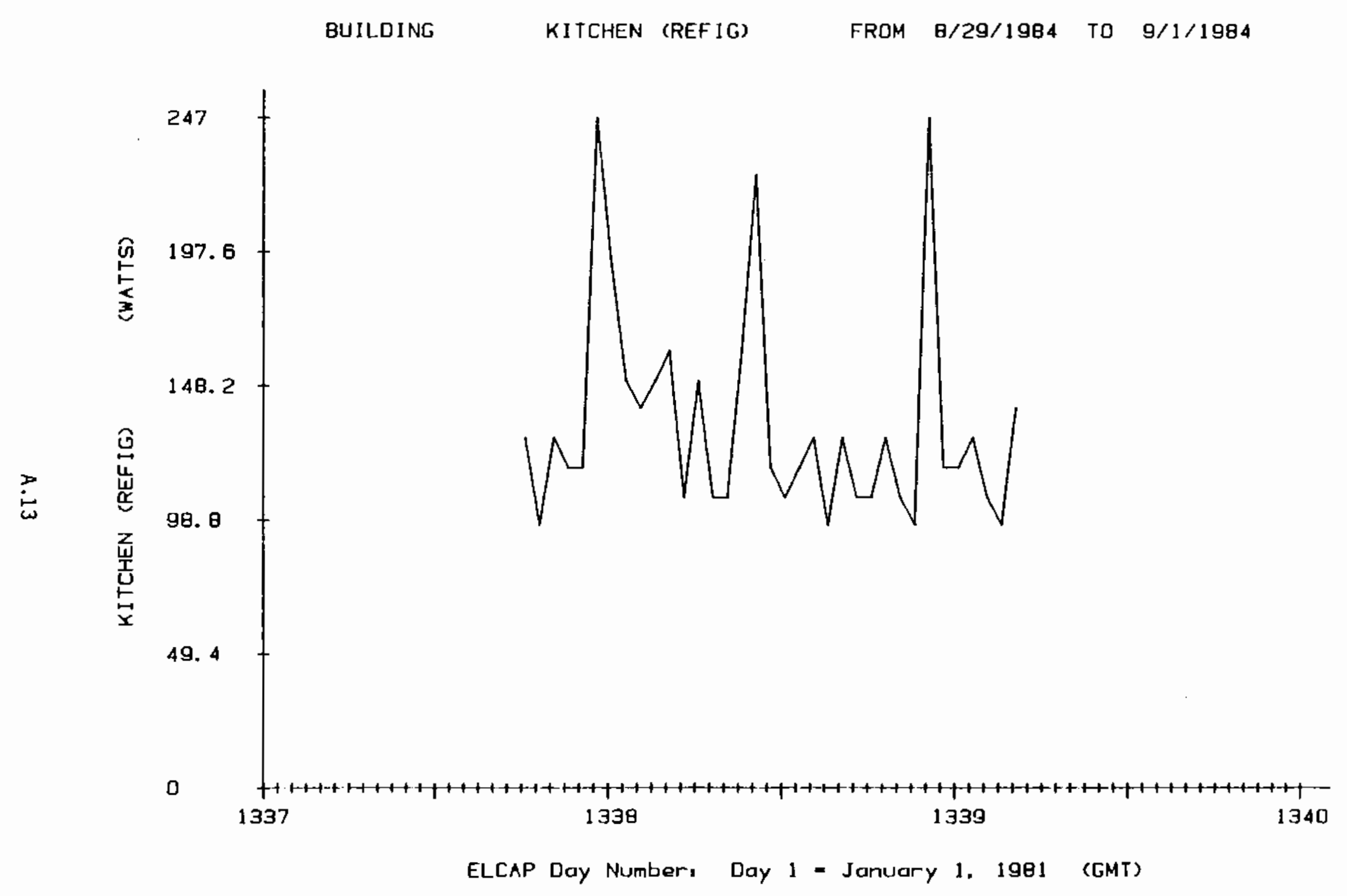

FIGURE A.2. Point-to-Point Plot Produced for the Refrigerator Using Option ' $C$ ' 
TABLE A.10. Day Number Tables Produced by the Main Routine ' $F$ '

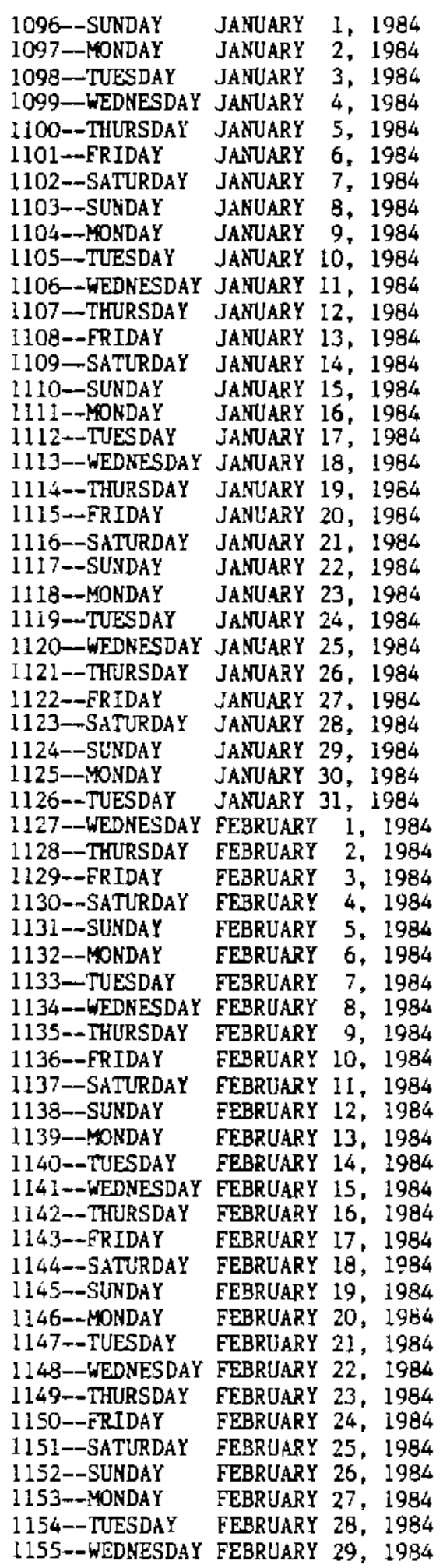

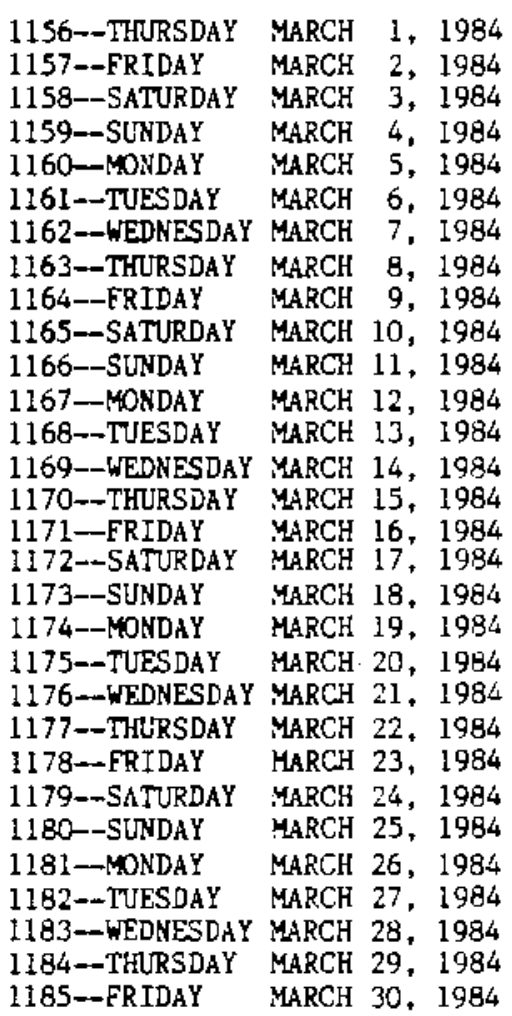


APPENDIX B

PROGRAM LISTING FOR TRANPLUS.BAS (SOURCE CODE) 


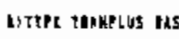

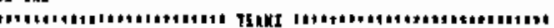

10014 16t"

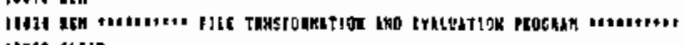

$10931 \mathrm{Cthht}$

'

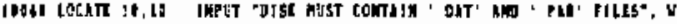

10110 oth asius?

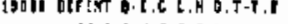

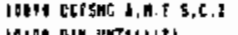

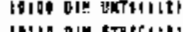

(1)

iIII)

(1114 gin tsecis

1015e bin soticil

Jall oin LEtcti?

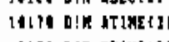

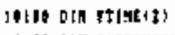

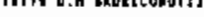

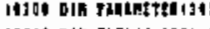

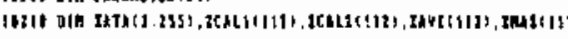

IIII $01 x$ I11

This dis

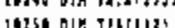

1934t a1x of 01121

10111 oth eywstils

10180 or etrsti1:?

IIII OIR STRTOSHIII

102) OER 33cattills

costs on tenronst

bels olk orthem,

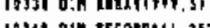

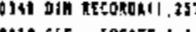

ntr

rat

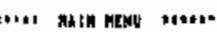

IE

CNOLI:

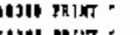

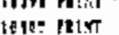

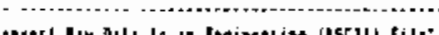

ill10 PUi4T

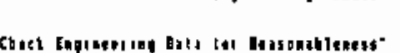

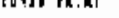

30130 nine

int m!kT

Inst paint

igcis aning.

1951, surs

IIt) istict

IASH ?n:ST

(1)il nist

10320 inist

$10531 \mathrm{B1} 1 \mathrm{xt}$

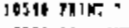

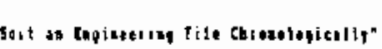

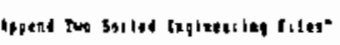

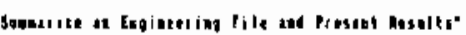

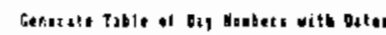

and n....

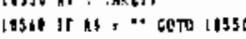




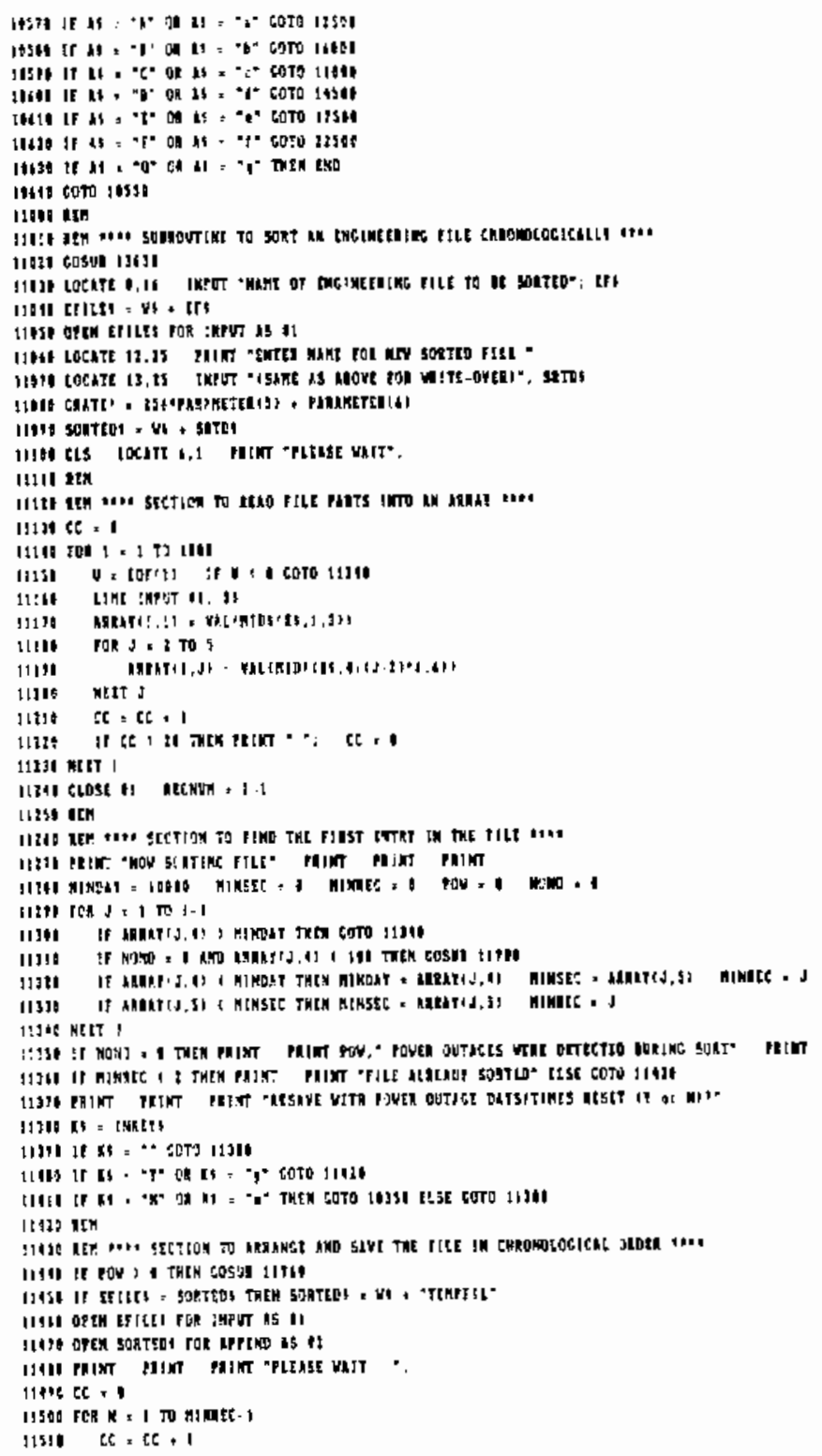




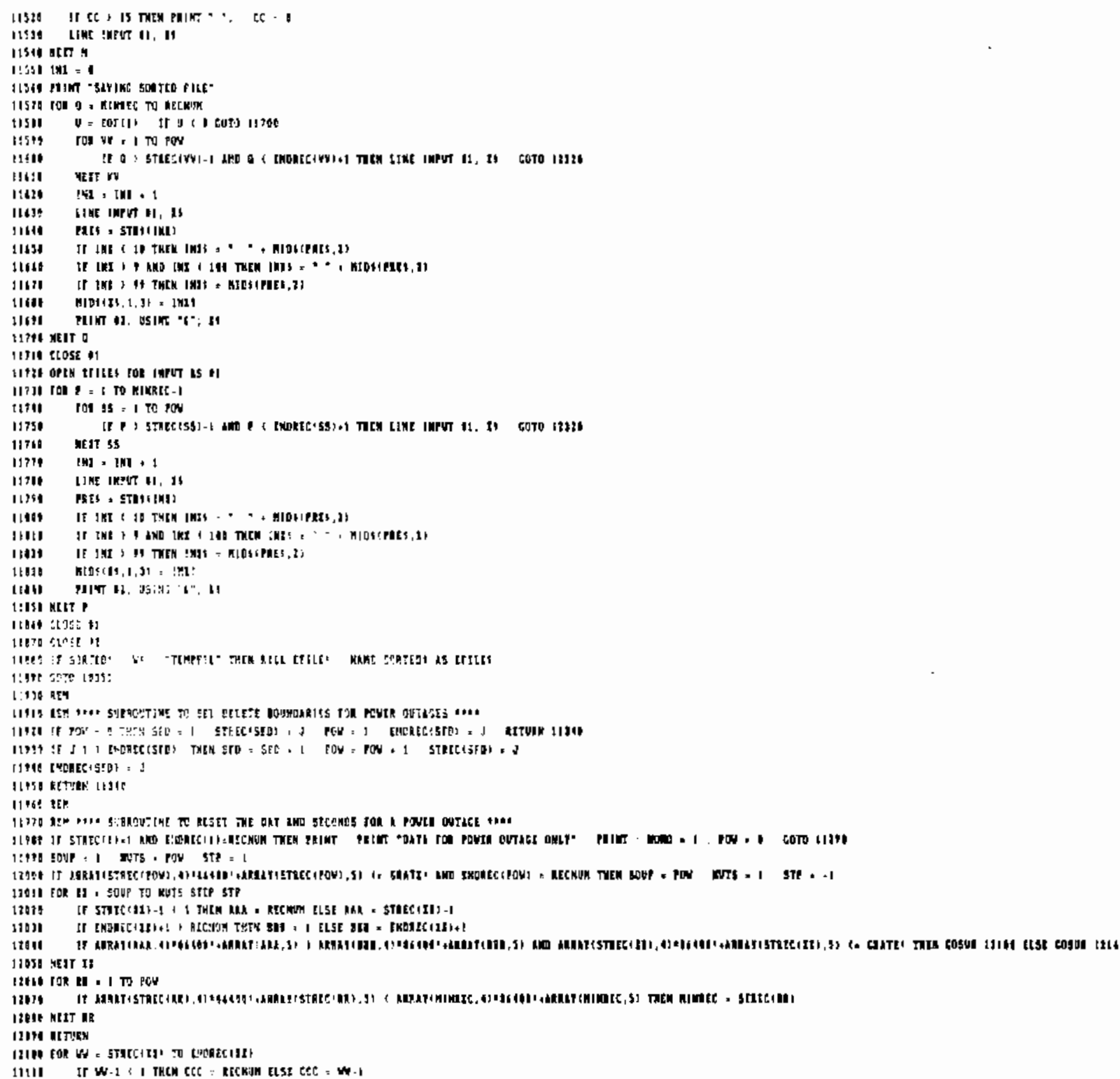




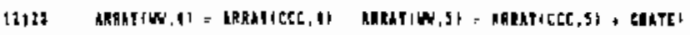

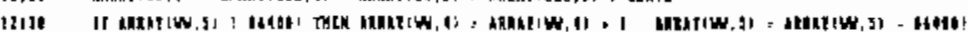

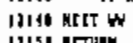

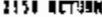

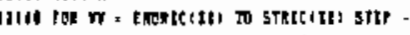

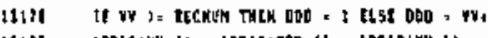

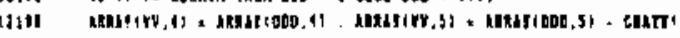

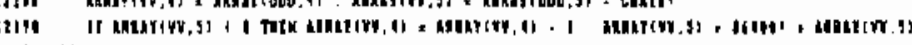

imit sttT ur

13210 netuan

11230

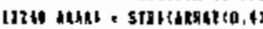

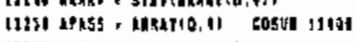

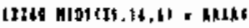

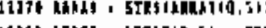

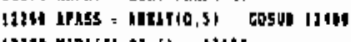

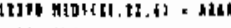

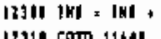

1310 С9T 11611

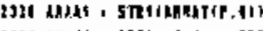

(13)

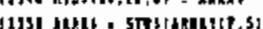

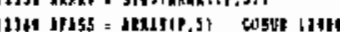

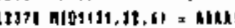

11361 $1 \mathrm{ME}:$ : $\mathrm{WE}$,

1:111 $6070117+1$

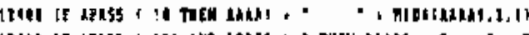

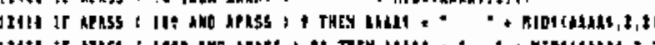

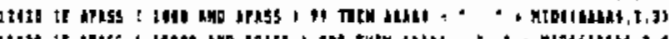

3ise

(I)

Lat+6 Mituma

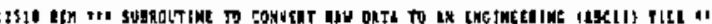

[3sis cosue isus!

(asus tecost 11.1

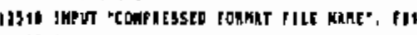

1355 " $"=23+105$

mon!men-1

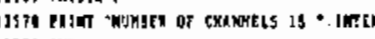

1331: : in:ake:-1

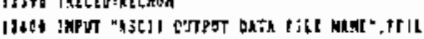

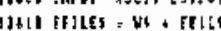

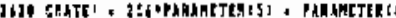

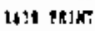

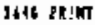

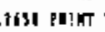

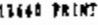

PLASE w15

$12610 \mathrm{Pher}$.

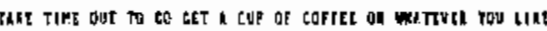

:

1306 aren in as at Len

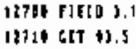

12710 CIT 0.5

(3):

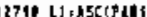




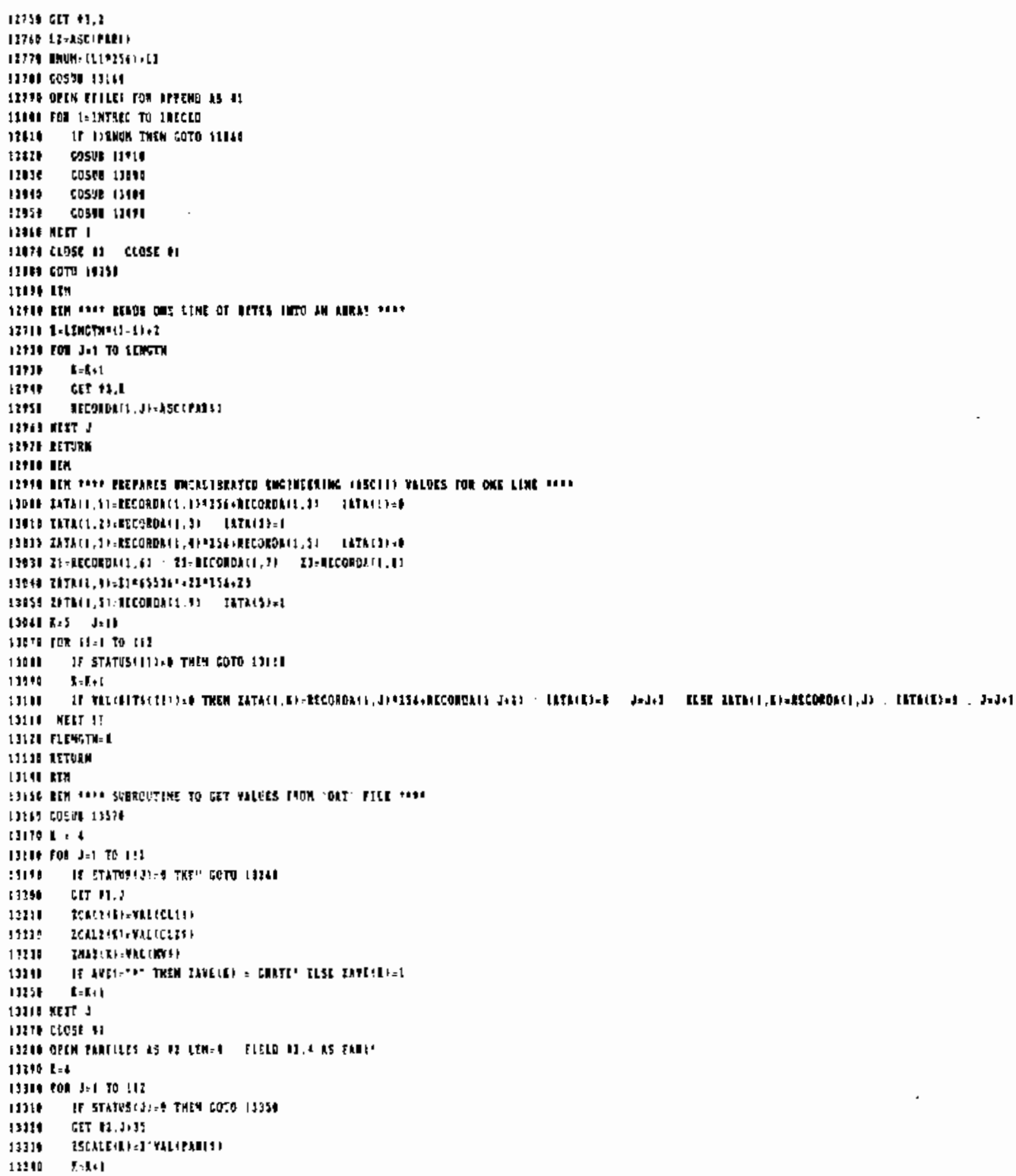




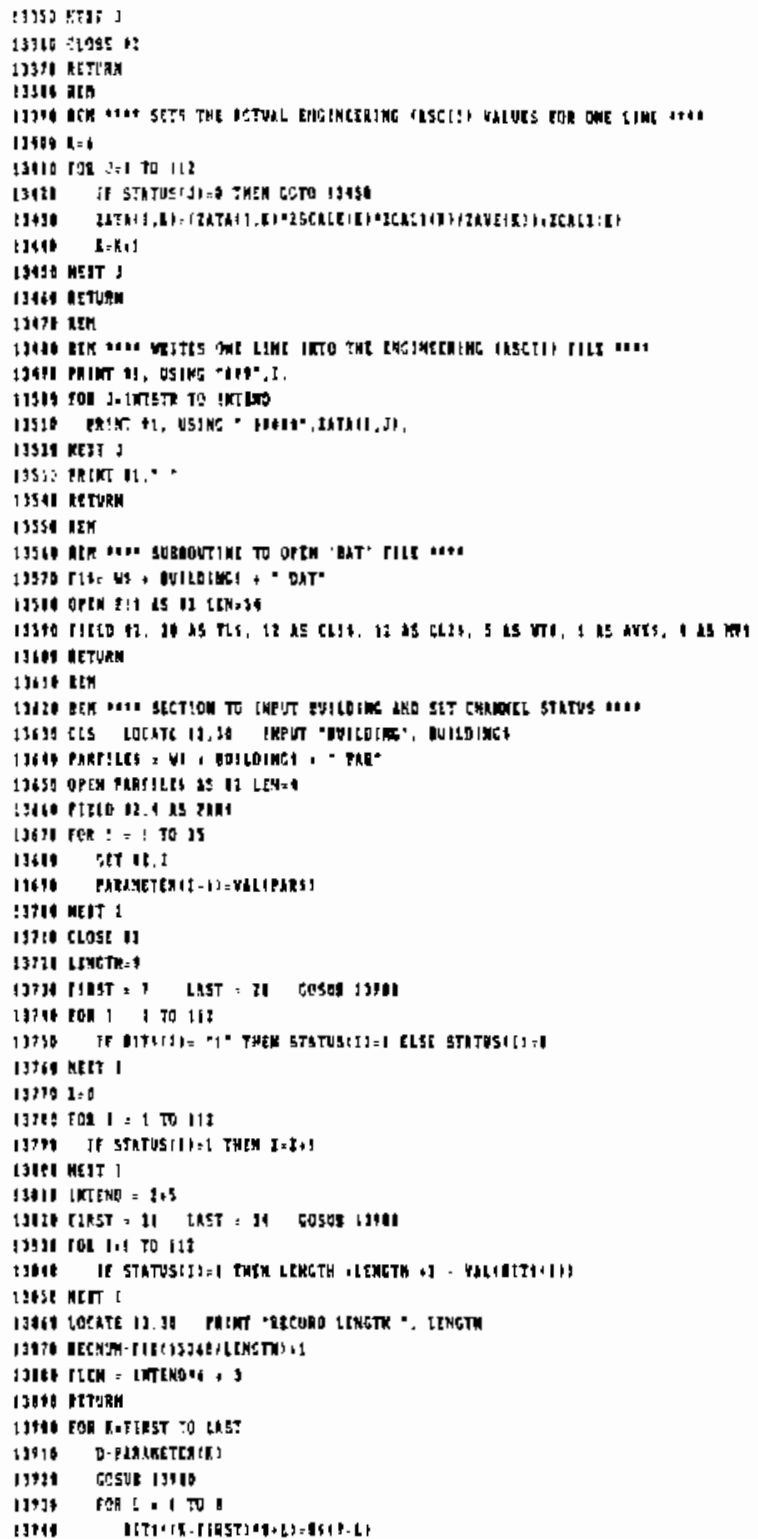




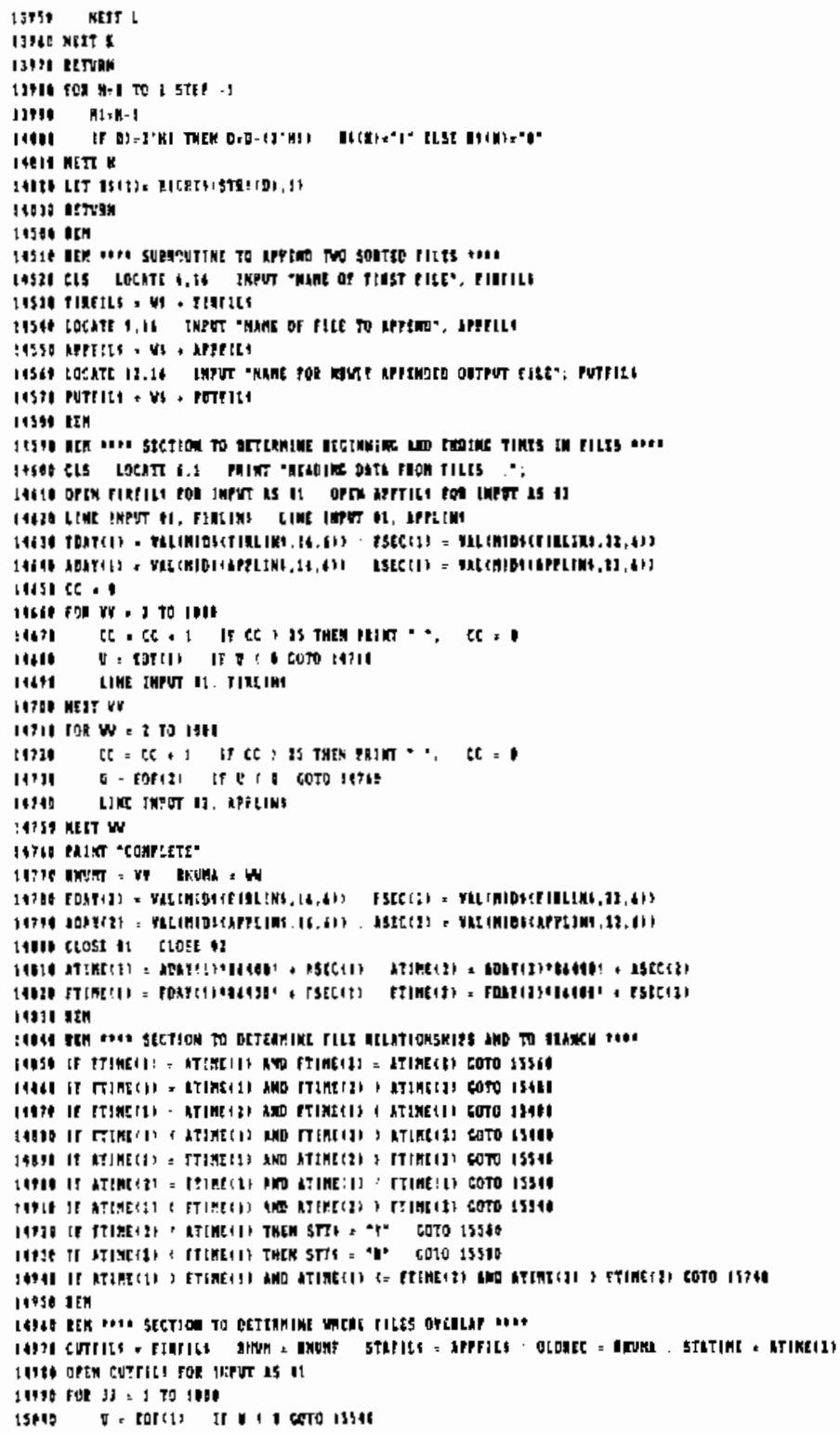




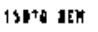

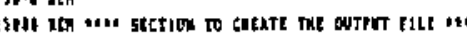

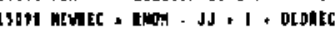

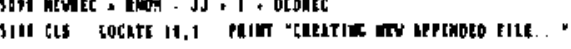

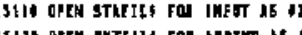

isise ic $=$ ?

1314 ete 11 , 1 go stores

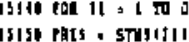

if 61 1 1 mon

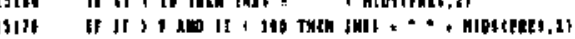

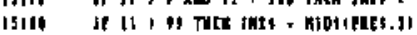

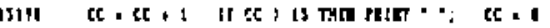

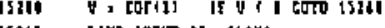

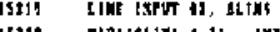

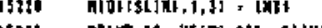

15r3: mint 13 .

ISTC Meit It

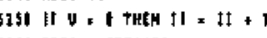

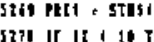

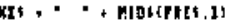

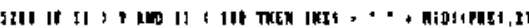

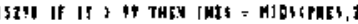

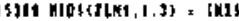

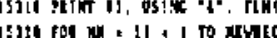

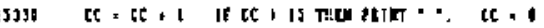

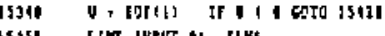

isss Lim Inert o1, rit

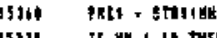

tyrm

$\therefore$.

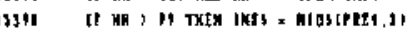

15At MIst

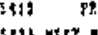

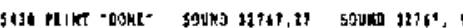

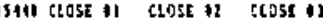

15:54 6070 211351

tsete ntK

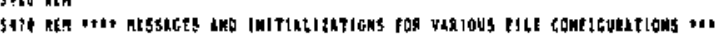

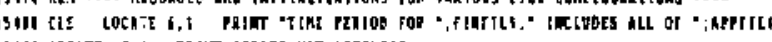

(3)

$1551061=$ :

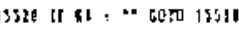

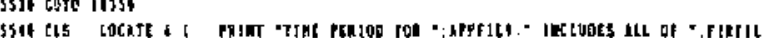

1ssso coso 15811

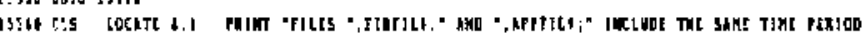

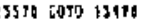

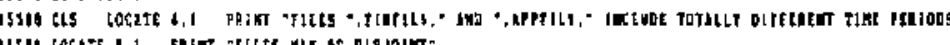

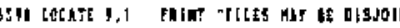

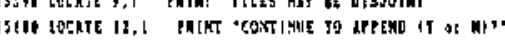




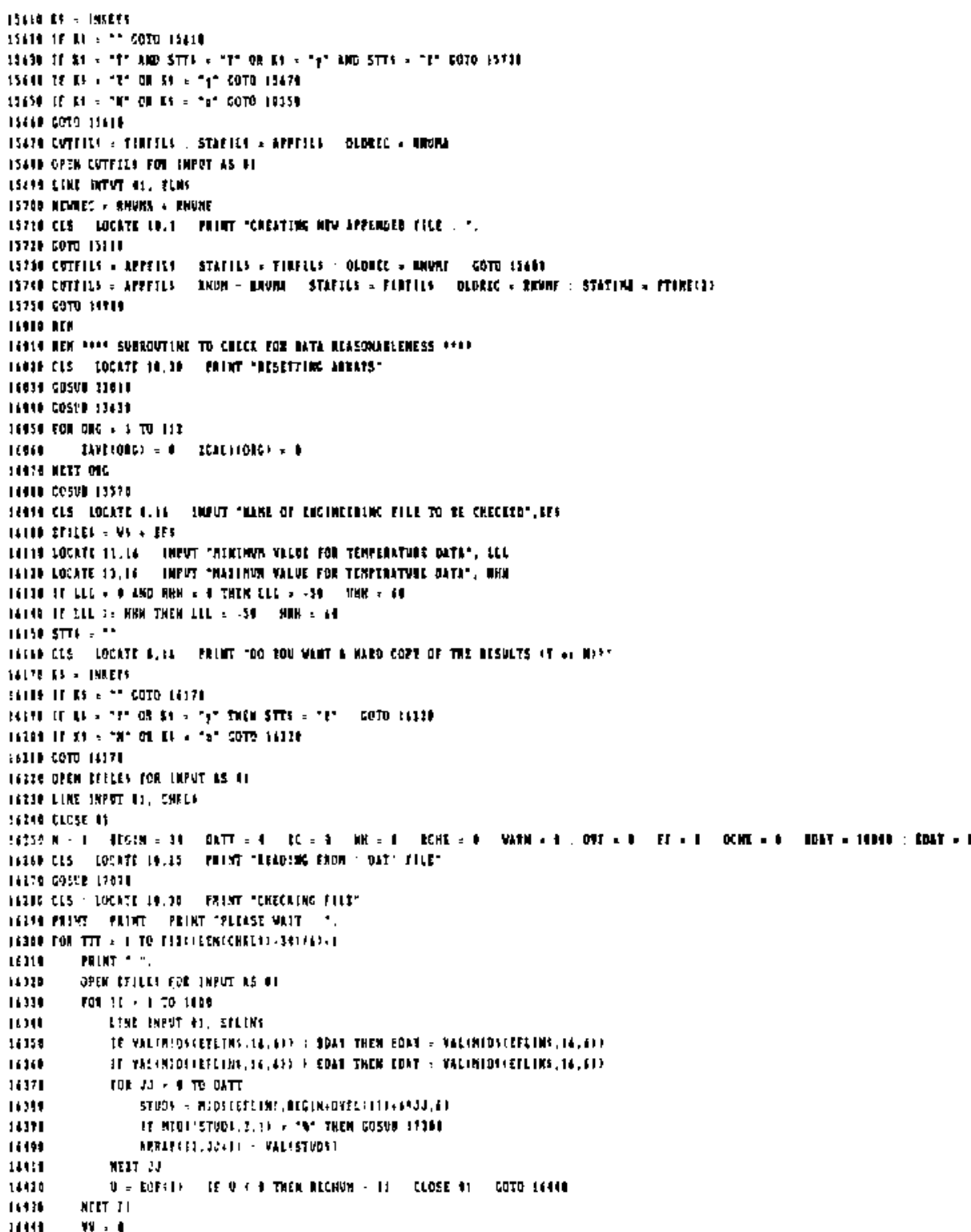




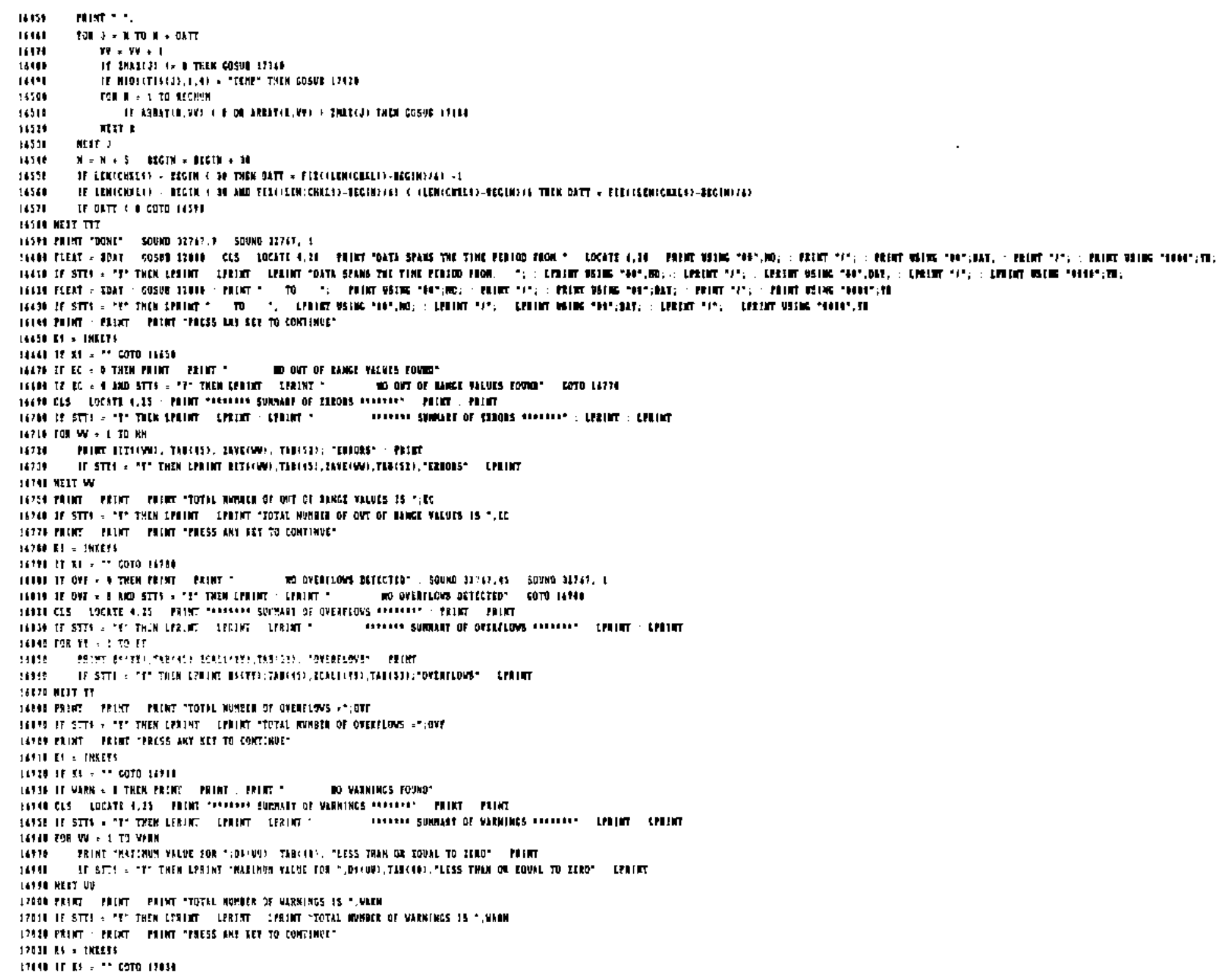




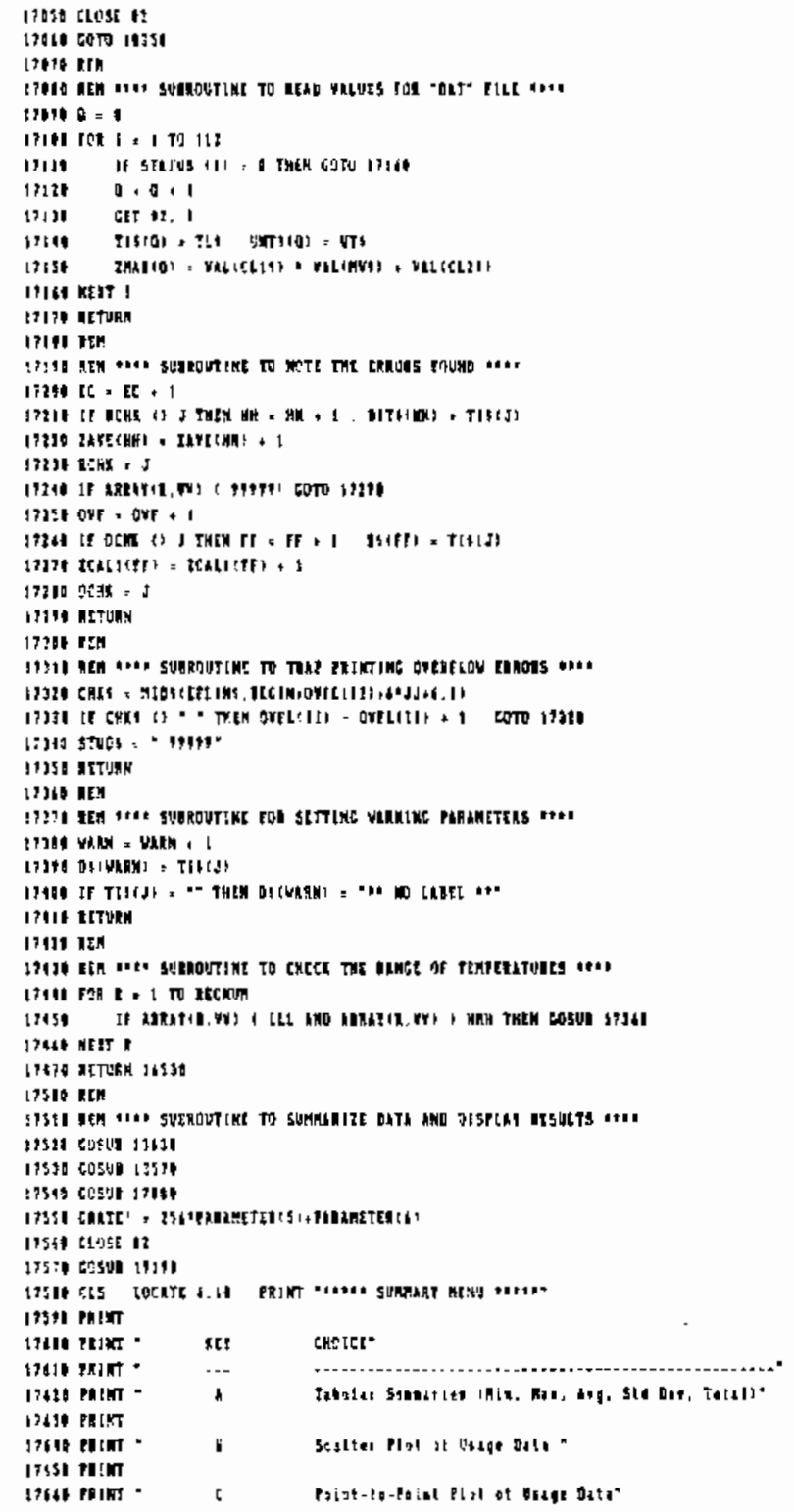




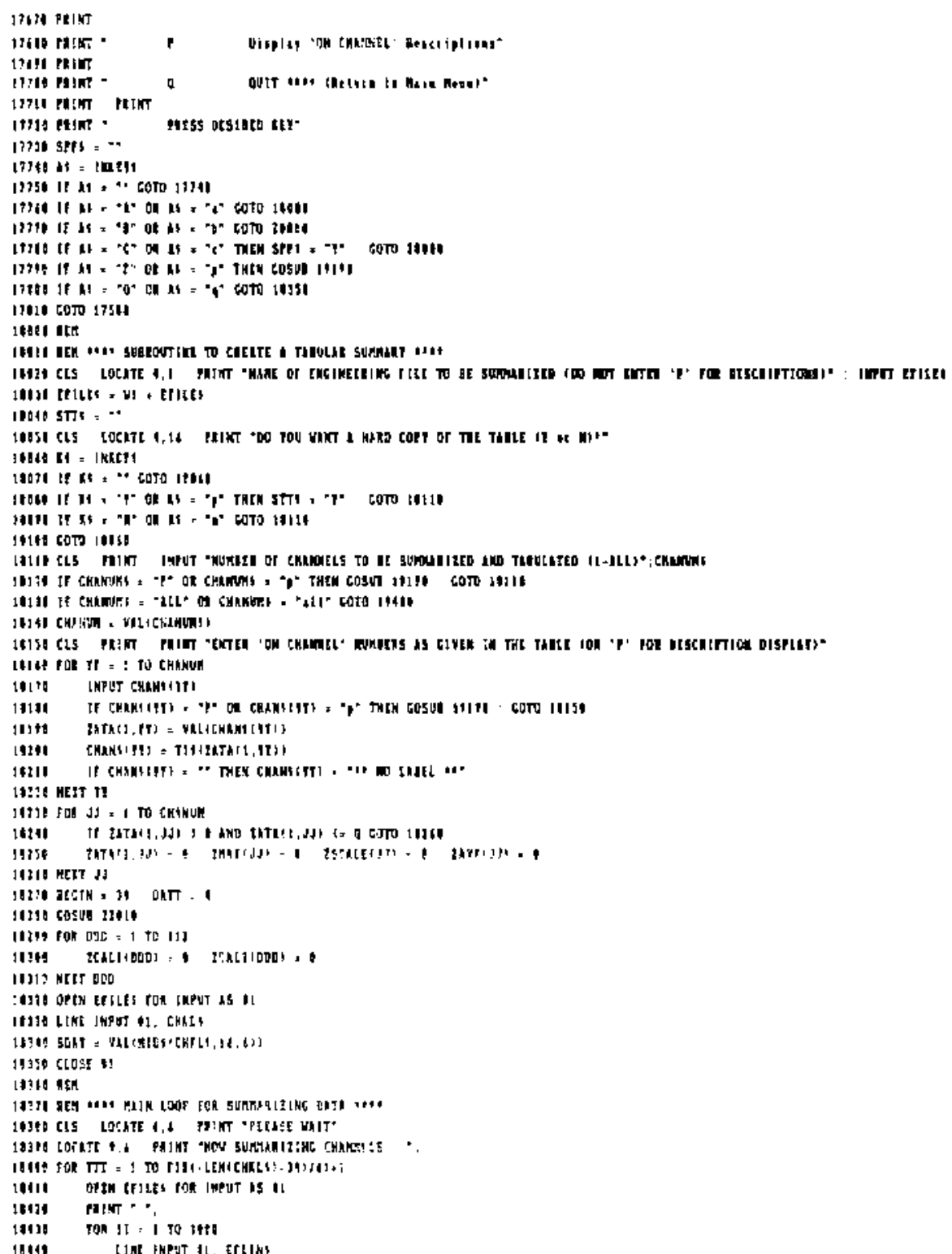




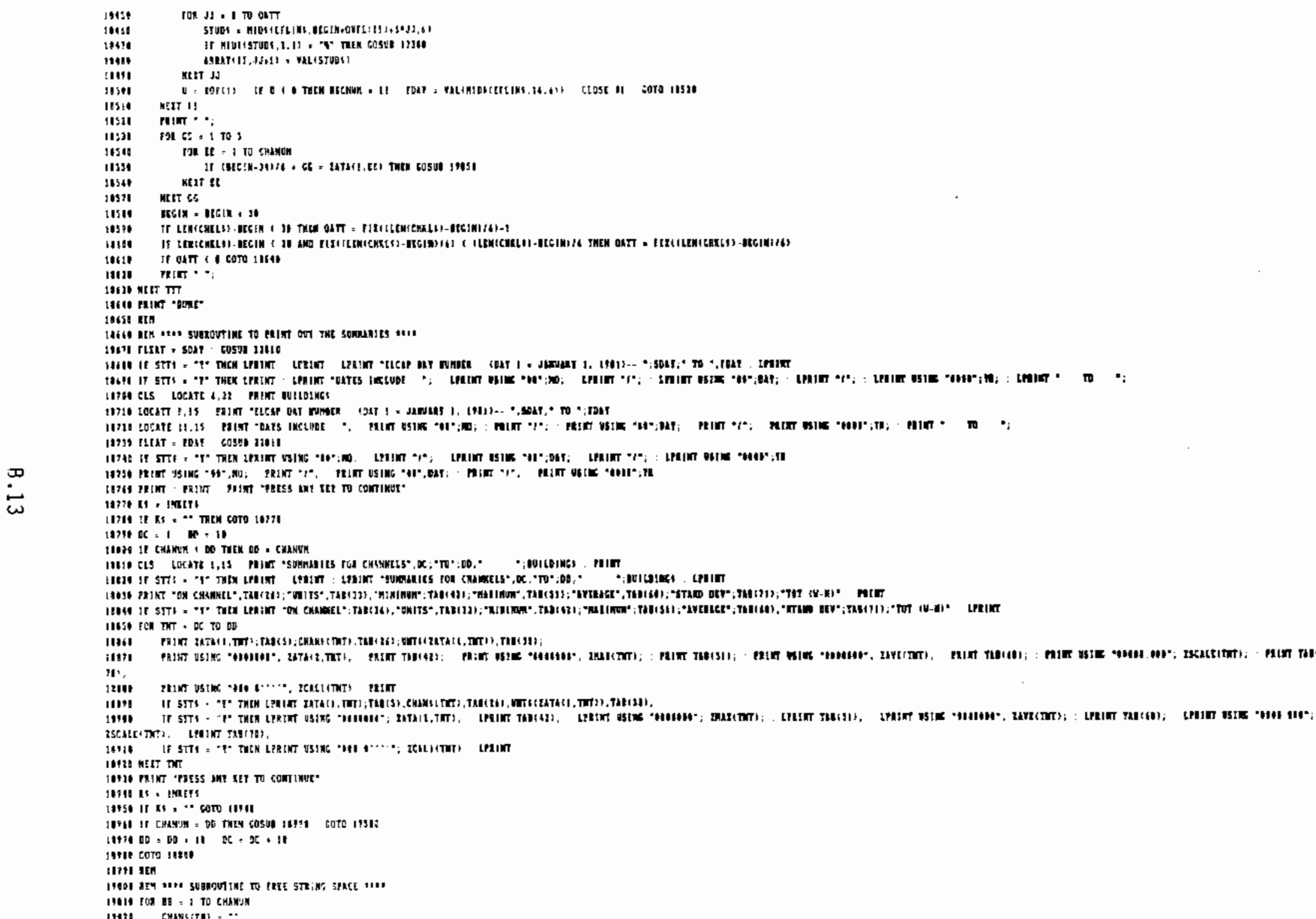




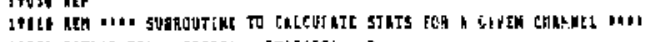

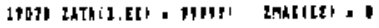

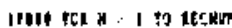

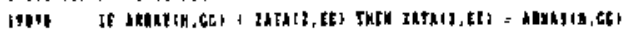

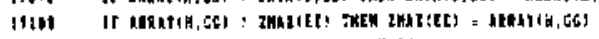

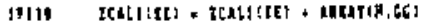

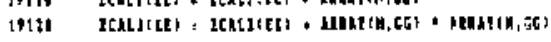

1113 तetr "

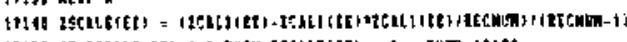

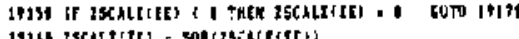

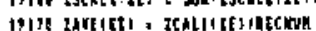

IIII tETh

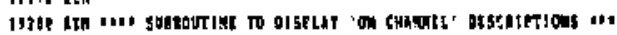

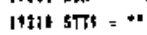

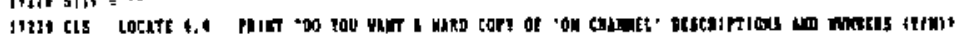

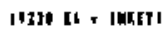

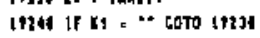

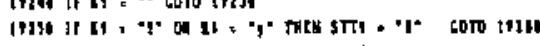

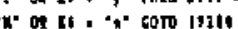

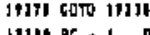

imit if $x=1$ if $00 \times 11$

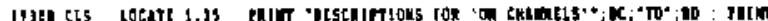

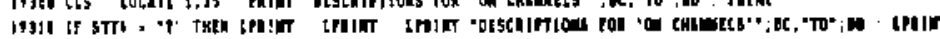

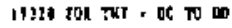

(10)

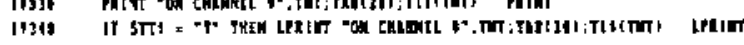

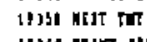

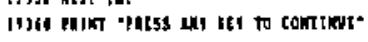

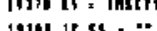

(1)

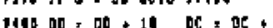

inis con tin!

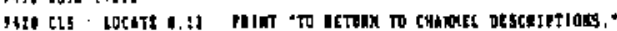

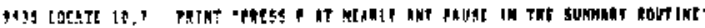

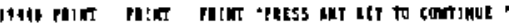

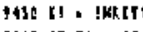

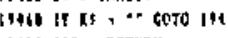

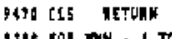

"1ilit tol mes = 1 to 9

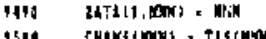

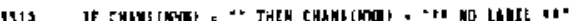

19נ1 nelt met

ins? inumut =

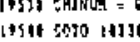

2004 ath

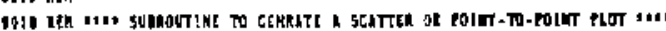

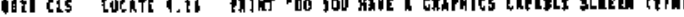

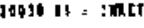

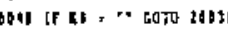

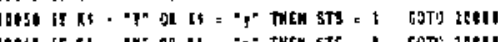

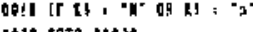




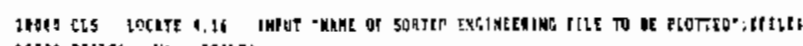

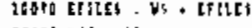

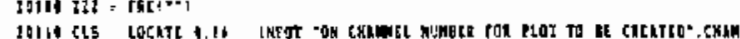

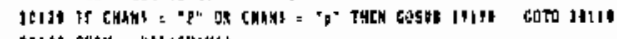

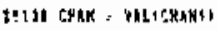

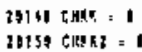

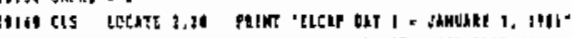

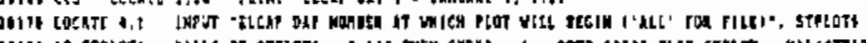

colio

ateris

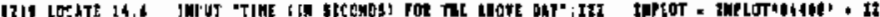

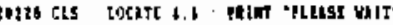

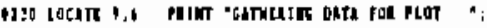

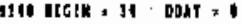

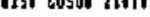

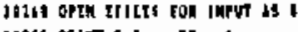

IIII) miste $\theta$, DF .

Imis tan $11=1$ no 1110

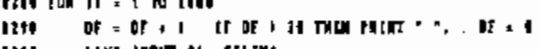

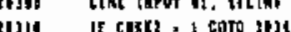

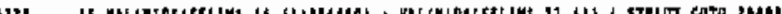

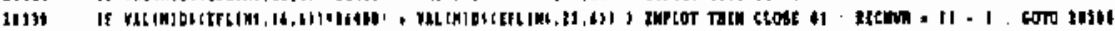

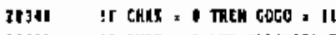

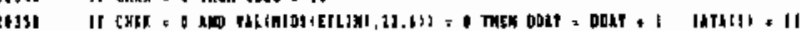

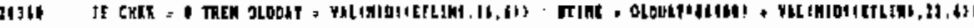

311" CALE $=1$

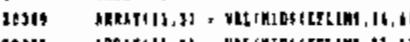

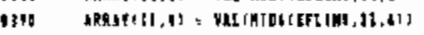

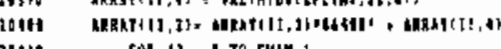

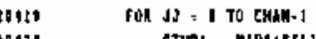

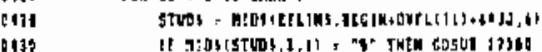

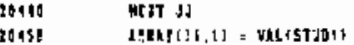

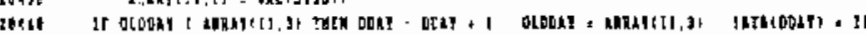

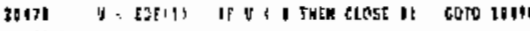

mill kit? It

jeted nesim , it

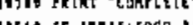

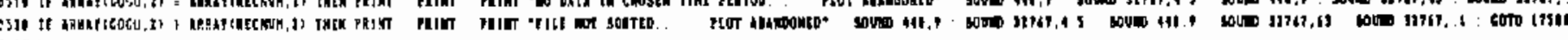

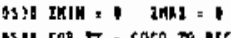

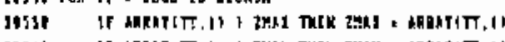

(2)

21:1e MEtт $\pi$

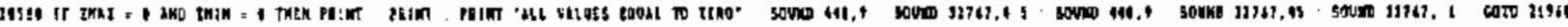

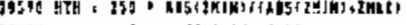

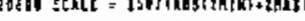

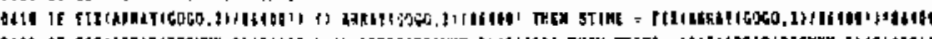

(20)

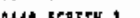

30

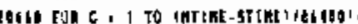

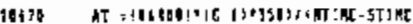


117ו MLIT :

31734 d113 =

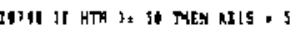

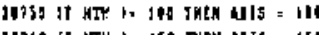

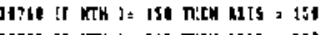

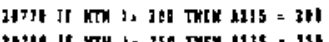

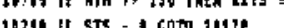

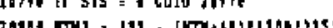

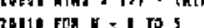

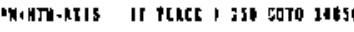

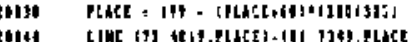

IUSS METT N

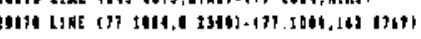

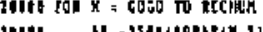

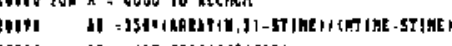

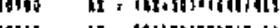

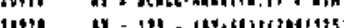

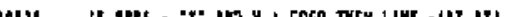

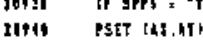

joss rest k

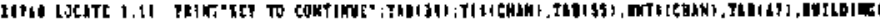

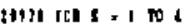

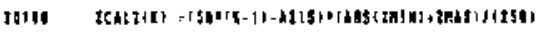

witl Men $\mathrm{K}$

1641 If sts - I coto 1311

:3it " = :

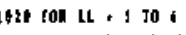

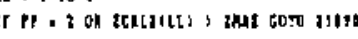

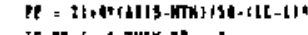

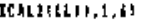

$318 \% 1$ cochit $m, 1$

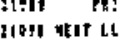

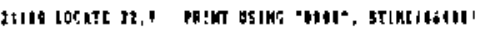

11:11 $35:=1$

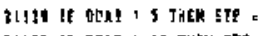

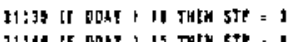

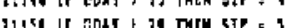

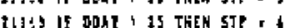

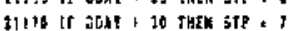

zills if $5 T 5,1$ coro 3111

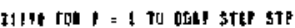

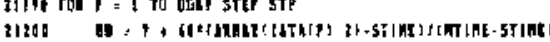

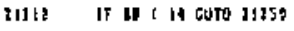

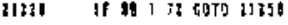

31330 tecust 12.63

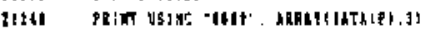

tiass पets :

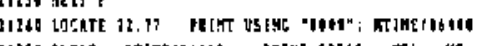

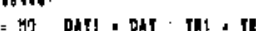




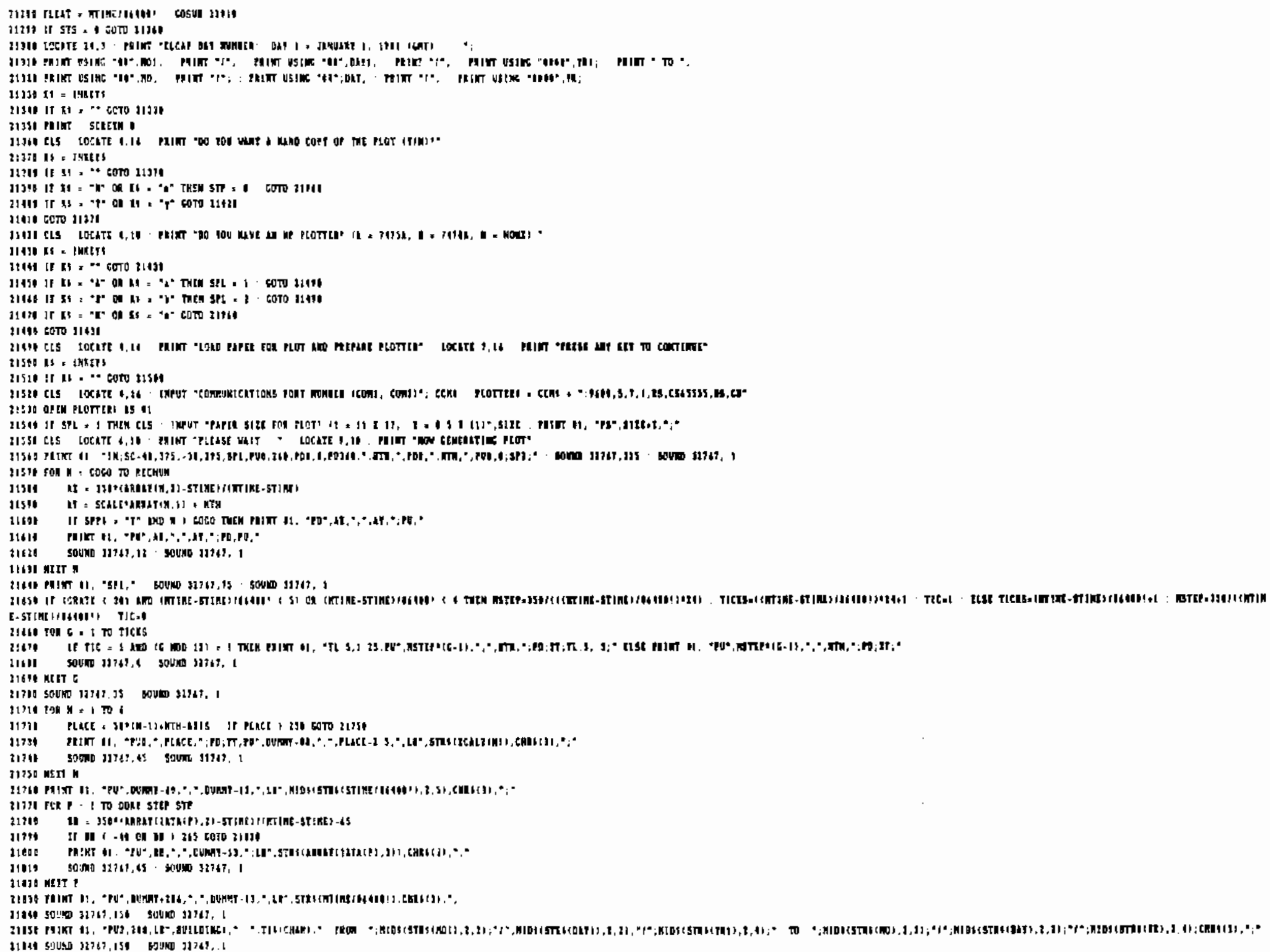




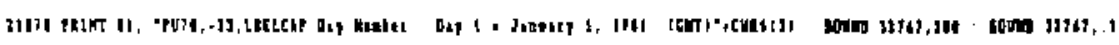

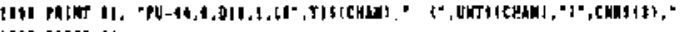

iltiv cis

3ill Es r mats"

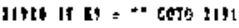

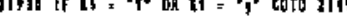

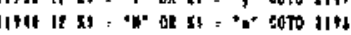

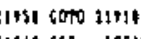

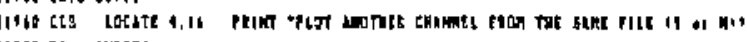

?1+11 13 = Inters

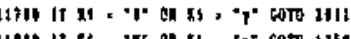

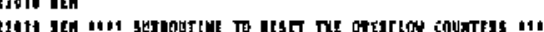

31139

most orgtoncive

tust kely onc

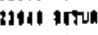

"ust Itก

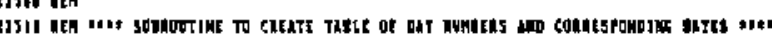

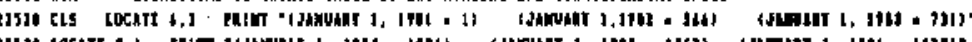

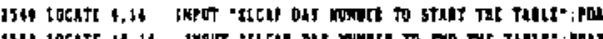

zusic skip = it

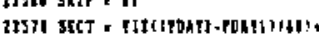

issen etsect =

"3s" Lea!T calstius

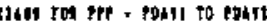

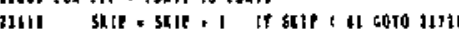

3i14 cestct + Cestct

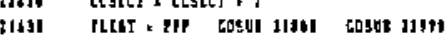

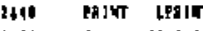

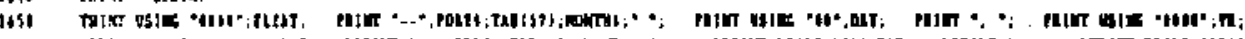

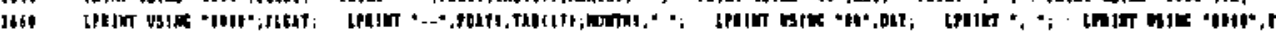

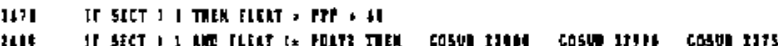

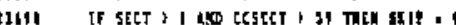

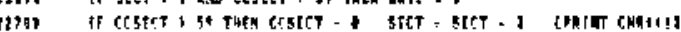

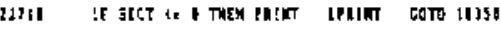

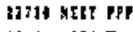

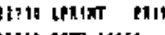

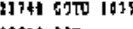

1:Th Itr

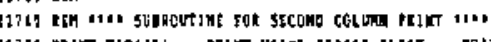

-

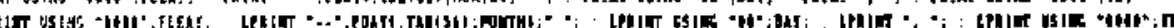

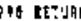

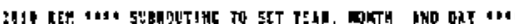

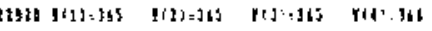

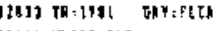

11340 mite $940: 146$

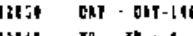

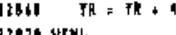

ment vemi

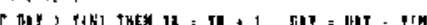




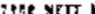

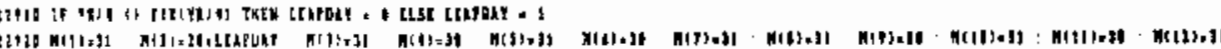
jim: $\rightarrow=1$

mert ren * $=1$ to 1 :

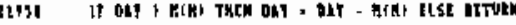

$121,4=\pi \cdot 1$

sime neit *

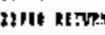

211" IEK

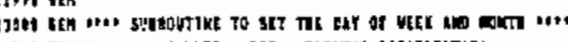

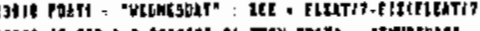

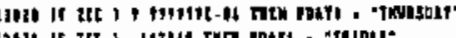

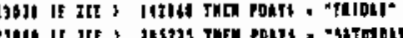

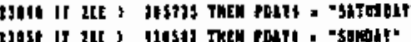

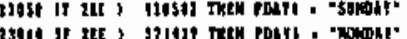

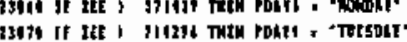

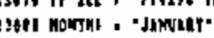

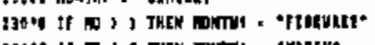

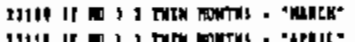

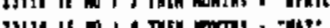

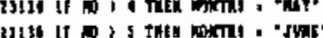

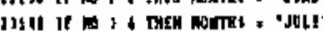

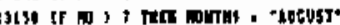

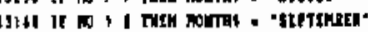

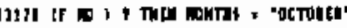

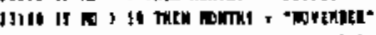

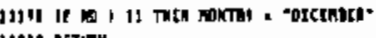


. 


\section{DISTRIBUTION}

No. of

Copies

OFFSITE

30 DOE Technical Information Center

K. J. Fischer

Department of Mechanical Engineering

Oregon State University

Corvallis, OR 97331

Dr. J. Welty

Department of Mechanical

Engineering

Oregon State University

Corvallis, OR 97331

Mr. Phil Wendell

BPA - KES

P.0. Box 3621

Portland, OR 97208

Mr. Michael Warwick

$B P A$ - KES

P.0. Box 3621

Portland, OR 97208
No. of

Copies

ONSITE

DOE Richland Operations Office

K. W. Bracken

23 Pacific Northwest Laboratory

S. G. Hauser

P. C. Hays

M. S. Klan

R. P. Mazzucchi

G. B. Parker

W. F. Sandusky (5)

G. J. Schuster

T. J. Secrest

D. R. Simpson

G. M. Stokes

R. A. Stokes

J. J. Thomas

Publishing Coordination (2)

Technical Information (5) 
$=$ 